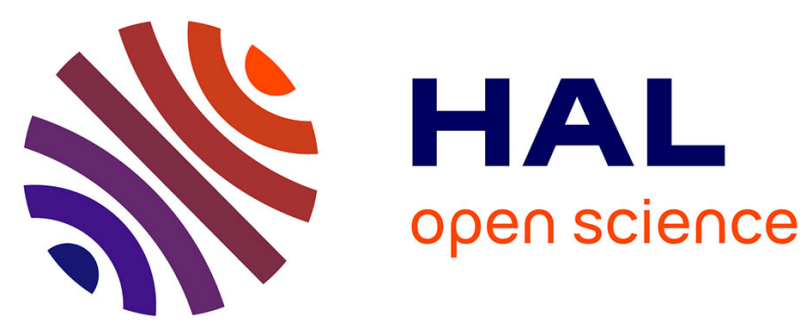

\title{
Point-record driving licence and road safety: an economic approach
}

Jean-Marc Bourgeon, Pierre Picard

\section{To cite this version:}

Jean-Marc Bourgeon, Pierre Picard. Point-record driving licence and road safety: an economic approach. Journal of Public Economics, 2007, 91 (1-2), pp.235-258. hal-00243024

\section{HAL Id: hal-00243024 \\ https://hal.science/hal-00243024}

Submitted on 6 Feb 2008

HAL is a multi-disciplinary open access archive for the deposit and dissemination of scientific research documents, whether they are published or not. The documents may come from teaching and research institutions in France or abroad, or from public or private research centers.
L'archive ouverte pluridisciplinaire HAL, est destinée au dépôt et à la diffusion de documents scientifiques de niveau recherche, publiés ou non, émanant des établissements d'enseignement et de recherche français ou étrangers, des laboratoires publics ou privés. 


\section{ECOLE POLYTECHNIQUE}

CENTRE NATIONAL DE LA RECHERCHE SCIENTIFIQUE

Point-record driving licence and road safety : an economic approach

Jean-Marc Bourgeon

Pierre Picard

June, 2005

Cahier nº 2005-035

\section{LABORATOIRE D'ECONOMETRIE}

1rue Descartes F-75005 Paris

(33) 155558215

http://ceco.polytechnique.fr/

mailto:labecox@poly.polytechnique.fr 


\title{
Point-record driving licence and road safety : an economic approach
}

\author{
Jean-Marc Bourgeon ${ }^{1}$ \\ Pierre Picard ${ }^{2}$
}

June, 2005

Cahier $n^{\circ}$ 2005-035

Résumé: Les permis de conduire à points sont aujourd'hui très largement utilisés pour faire respecter les politiques de sécurité routière, avec toutefois des mises en oeuvre diverses selon les pays et parfois à l'intérieur d'un même pays. Comme toute sanction non-monétaire, priver les contrevenants de leur permis permet aux autorités publiques de retirer de la route les individus dangereux et aussi de dissuader les conducteurs normaux d'enfreindre le code de la route. Nous analysons les caractéristiques souhaitables des mécanismes de permis à points et, en particulier, nous étudions s'ils devraient inclure des clauses de récupération des points perdus et des périodes probatoires. Nous envisageons également la possibilité d'un retrait immédiat du permis de conduire pour les infractions les plus graves.

\begin{abstract}
Point-record driving licences are widely used nowadays to enforce road legislations, but with diverse implementations from one country to the other, and even within a country. As any non-monetary sanction, depriving offenders from their licences allows the Government to incapacitate dangerous individuals and also to deter normal drivers to infringe road legislation. We investigate the desirable features of point-record licence mechanisms, and in particular, if they should allow drivers to redeem their points and/or include probationary periods. We also consider the possibility of an immediate withdrawal of the driving licence for very serious offences.
\end{abstract}

Mots clés : $\quad$ sécurité routière, réglementation, permis de conduire

Key Words : $\quad$ road safety, law enforcement, driving licence.

Classification JEL: $\quad$ K320, K420, R410, R480

\footnotetext{
${ }^{1}$ INRA et Ecole polytechnique.

${ }^{2}$ Ecole polytechnique et HEC School of Management.
} 


\section{Introduction}

Road safety is one of the major public health concerns nowadays. According to the World Health Organization, more than one million people around the world die in road crashes and twenty millions are injured or disabled by roadtraffic injuries each year. This is a big challenge for developing countries, but also for the OECD countries, where more than 116,000 people died in car crashes in 2000.

As early as the mid seventies, the benefits of legislations focusing on structural improvements and on inboard devices of active and passive safety were questioned by statistical analysis. ${ }^{1}$ Accordingly, the basic tenet among OECD countries on the cause of road insecurity has progressively evolved from infrastructure improvement and vehicle safety to the monitoring of drivers' behaviors and punishment for driving offences. In particular, measures taken in Britain, the Netherlands, Norway and Sweden have result in a cut of the fatality rate in road crashes to less than 7 per 100,000 of the population in 2000, while the average figure for all OECD countries (except Mexico and Slovak Republic) is 12.5 deaths per 100,000. Strong political commitment and the setting of specific safety targets in relation to speed, alcohol and the wearing of seat-belts form the basis of these successful measures. This demonstrates that at least in the OCDE countries, road insecurity nowadays is more the result of drivers' behaviors than the consequence of the poor state of roads and vehicles.

Punishments for the minor infringements of road regulations belong to two categories: monetary sanctions (fines and insurance payment) and licence deprivation (suspension or withdrawal). At first sight, we may think that monetary penalties should be preferred by governments. Indeed, the social costs of monetary penalties can be considered as negligible, since taxpayers benefit from the revenues generated by these policies, while the revocation of a driving licence does not benefit to another individual in society. However, there are two reasons justifying that governments do not limit their policy to monetary sanctions only. First, drivers may be insolvent, which limits the maximum amount governments may charge offenders and thus the power of the incentives provided by the policy. Second, drivers belong to a heterogeneous group of individuals, some being opportunistic, the others chronically reckless. Road safety legislations are thus impeded by both a moral hazard problem (to deter opportunistic drivers to infringe road

\footnotetext{
${ }^{1}$ See the work of Peltzman (1975) on the effect of the Road Safety Acts of the midsixties, and Blomquist (1988). These results are challenged by Graham et Garber (1984).
} 
regulations) and an adverse selection problem (spotting and incapacitating the individuals who are intrinsically reckless). While monetary sanctions may reveal efficient for deterrence purposes, only incapacitation strategies like licence revocation can diminish the number of chronic reckless individuals on the road. ${ }^{2}$

To avoid inefficient withdrawals, many countries have adopted pointrecord driving licence mechanisms. Their implementations are widely different from one country to another, even from one state to another in the US, but their general operating principles are the same. Depending on their seriousness, infringements are punished by the loss of one or several points, delaying the withdrawal of the licence to the exhaustion of the driver's pointcredit. $^{3}$

While they share similar general principles, the diversity of the systems is surprising. In the U.S., almost all states have adopted point-record systems but the total credit of points granted to drivers and the number of points removed for the same violation differ widely from one state to the other (from two to six points in Wisconsin, one to twelve in Maryland, one or two in California). Once the point credit is exhausted, the driver may have to go to an interview and an analyst decides which is the best decision to take against the offender, from a warning letter to the withdrawal of the licence. In other countries (like France since 2002), the withdrawal of the licence is automatic once the point-record credit is exhausted.

We propose to analyze point-record systems to exhibit the desirable features they must include to enlarge social gains. We investigate and compare several instances of effective mechanisms, i.e. point-record mechanisms inducing individuals to drive sanely whatever their records. We suppose that cautious driving increases the social welfare while reckless driving diminishes it. In addition to be not too costly to administer, the optimal system must allow the Government to remove reckless individuals from the roads while inducing normal ones to drive carefully. In other words, point-record driving licences play a double role: they are at the same time a screening

\footnotetext{
${ }^{2}$ For the use of nonmonetary sanctions as deterrent and incapacitation devices, see Shavell (1987a and 1987b) and Kaplow (1990). See also Polinsky and Shavell (2000) for a presentation of the economic theory of public enforcement of law.

${ }^{3}$ In some states of the US or in Canada, drivers may have "demerit points" on their record. In such a system, a driver begins with zero demerit point and accumulates demerit points for convictions. Once the number of demerit points has reached a threshold, the licence is suspended for a given period. We here consider the system - most frequently used in Europe - where drivers lose points due to convictions for certain traffic offences and they lose their licences when their point record is exhausted. Of course, both systems are equivalent.
} 
and incapacitating device and a deterrence mechanism. In what follows we analyze this double function within a model with two types of drivers called reckless drivers and normal drivers. Reckless drivers (e.g. alcoholics or persons showing a propensity for road aggressiveness) are not sensitive to the incentives of the point-record system because their disutility of careful driving is very large. On the contrary, normal drivers abide by the road regulations if the incentives to do so are large enough.

As an incapacitating device, point-record driving licences act in two ways. Firstly, the drivers who have lost all their points may have to pass an exam to get their licence back (after the compulsory deprivation period) and some reckless drivers (e.g. mentally unstable persons or chronic alcoholics) may be spotted and prevented from driving. Secondly, reckless drivers will lose their points more rapidly than normal drivers, and the proportion of reckless individuals among the drivers will be reduced by this selection mechanism. Point-record driving licences also deter normal drivers to infringe the Highway Code even if this is costly in psychological or monetary terms (e.g. not to drive faster than the speed allowed by law, even if you are late with an important business meeting!).

We show that these incapacitating and deterring functions and the cost of driving licences examinations lead to an optimal system characterized by the number of points that should be initially attributed to a driver and by the length of the deprivation period for those who have lost their last point. This optimal system depends on several parameters, including the proportion of reckless drivers in the population, the probability for each type to commit a road infraction and their probability of success at the driving licence examination as well as the administrative costs of these examinations. We also show that the government may have reasons to forbear from implementing the optimal point-record mechanism: we analyze the nature of this difficulty and we establish that the optimal system requires the commitment of the government to withdraw the driving licences of offenders when the proportion of reckless drivers is low.

Several features may be included in road regulations. One possibility investigated is the "redemptive" system, where drivers can redeem points by driving carefully, i.e. after a given period without driving offence. Without redemption, drivers can only loose their points. With these rather tough systems, even careful (but not infallible) individuals end up deprived of their licence. Like other drivers, their are entering a punishment phase the length of which may depend on their ability to pass health, driving and written examinations. Compared to tougher systems, we show that redemptive point-record licences increase the social welfare. 
New drivers (particularly young people) may also be subject to special treatments. In particular, they may have to demonstrate their ability to drive during a probationary period before being granted a full credit of points. This transient phase helps the authorities to discriminate between dangerous and normal drivers. It may be completed with a reduced-credit licence for beginners who fail to cross the transient phase without indictment. We analyze such a system and demonstrate that it increases the social welfare. On the whole, systems including probationary periods and reduced-credit licences allow the government to incapacitate more frequently dangerous drivers because they strengthen the screening efficiency of pointrecord driving licences.

As road infringements are diverse in their nature (speed, aggressive driving, poor state of the car, ...) and may be more or less acute depending of their intensity, we also investigate the desirable features of point-record licence systems when the seriousness of road infringements varies. In particular, we establish conditions under which it is socially optimal to withdraw the licences of drivers who commit very serious driving offences. This is the case when the most serious driving offences are strongly informative on the offender's behavior. Indeed, in such a case, the social benefits of incapacitating reckless drivers prevail over the cost of evicting some normal drivers who (say because of a momentary lack of attention) may have committed a very severe infringement.

The rest of the paper is organized as follow. In Section 2 we set up the basic model, we establish the existence of an optimal point-record mechanism and we derive its most important properties. Section 3 considers more elaborated versions of the point-record mechanisms, including redemptive systems and probationary licence system. Section 4 extends the model to the case where the seriousness of driving offences varies and contemplates the option of an immediate withdrawal of the driver's licence for very serious offences. All proofs are gathered in the appendix.

\section{The basic model}

Let $e$ be the driver's effort. For simplicity, we assume that $e$ may only take two values, either 0 or 1 . We distinguish between two kinds of drivers, namely "normal" drivers, who may exert an effort $e=1$ (i.e. driving carefully) provided that the point-record mechanism gives adequate incentives (in such a case, we will say that the record mechanism is effective), and highrisk "reckless" drivers, whose driving effort is always $e=0$. With effective 
regulations, there is a one-to-one correspondence between drivers' efforts and types, normal drivers always exerting an effort $e=1$ and reckless drivers choosing $e=0$. We shall thus refer to the drivers' type by calling them type-e drivers. Effort determines the probability that a driver infringes road regulations and more precisely the probability $p_{e} d t$ she is caught committing an infraction during an infinitesimal length of time $d t$, with $p_{0}>p_{1}>0$. A type-e driver is thus caught violating road regulations during a time-period of length $t$ with probability $\int_{0}^{t} p_{e} e^{-p_{e} \tau} d \tau=1-e^{-p_{e} t}$, which corresponds to an expected time $1 / p_{e}$ between two punishments for road infringement. In other words, the time period between two infractions follows an exponential law with parameter $p_{e}$. When convicted, the driver's point-credit is reduced by 1 . A fresh record entails a $N$ points credit, which is also the maximum a record can reach. It may be reduced to 0 , which leads to the withdrawal of the driver's license. Driving yields an instantaneous private gross utility $\bar{v}$ to the driver, while exerting an effort $e=1$ entails a disutility $k$ to normal drivers, with $\bar{v}>k>0 . \bar{v}$ and $k$ are in monetary units, i.e. $\bar{v}-k$ measures the economic private surplus of normal drivers when they drive carefully. Implicitly, the cost of providing effort is very large for reckless drivers, so that they never exert effort whatever the point-record system. Drivers maximize the expected discounted sum of their lifetime utility.

Punishment in this driver-record system corresponds to the withdrawal of the licence. An exhausted credit may be reinstated after time-period $T$, assuming that the driver qualifies for a new licence, i.e. she passes visionhealth, written and road examinations and possibly an interview and psychological tests. Examinations are a screening device: a type-e driver passes with probability $\eta_{e}$ with $0<\eta_{0} \leq \eta_{1} \leq 1$. A driver who fails has to wait for another time period $T$ before taking the exam one more time. Successful candidates are reinstated to a $N$ points fresh record. Utility is null when drivers are deprived of their licence.

\subsection{Incentives for careful driving}

The derivation of the incentive constraint for careful driving proceeds in two steps. In the first step, we compute the lifetime expected utility of a normal driver who chooses to drive carefully (i.e. who chooses $e=1$ ) as a function of her point-record. In the second step, we derive the conditions under which the driver has no advantage in deviating from this behavior whatever her point-record.

With a current record of $n>0$ points, the expected utility $u_{n}$ of a normal 
driver exerting an effort $e=1$ is given by

$$
u_{n}=\int_{0}^{+\infty} p_{1} e^{-p_{1} \tau}\left(\int_{0}^{\tau}(\bar{v}-k) e^{-r t} d t+e^{-r \tau} u_{n-1}\right) d \tau
$$

where $\tau$ is the (unknown) date at which the driver is caught committing an infraction, and $r$ is the discount rate. The driver's expected lifetime utility is the discounted sum of her immediate satisfaction of driving, i.e. $(\bar{v}-k) e^{-r t}$ at time $t$, with $t$ varying from the present $(t=0)$ until the date $\tau$ where she is convicted, loses a point and thus gets the present value of her expected future utility with a $(n-1)$-point record, $e^{-r \tau} u_{n-1}$. Date $\tau$ depends on the way she is driving : by exerting an effort $e=1$ the probability she is not convicted at this date is $e^{-p_{1} \tau}$, which decreases over an infinitesimal period of length $d t$ by $p_{1} e^{-p_{1} \tau} d t$. Integrating (1) yields the recursive expression

$$
u_{n}=\frac{\bar{v}-k+p_{1} u_{n-1}}{r+p_{1}}
$$

This is easily interpreted by considering the equivalent relationship

$$
r u_{n}=\bar{v}-k-p_{1}\left(u_{n}-u_{n-1}\right)
$$

which states that the instantaneous driver's welfare $r u_{n}$ is composed of two terms: her immediate driving surplus $\bar{v}-k$ and the expected change in her utility level due to the change in her point-record $-p_{1}\left(u_{n}-u_{n-1}\right)^{4}$

Denote by $u_{0}$ the expected utility of a normal driver who has just been deprived of her licence (i.e. who has just lost her last point). A type-e driver is reinstated after punishment period $\theta T$ with probability $\eta_{e}\left(1-\eta_{e}\right)^{\theta-1}$, where $\theta \in \mathbb{N}^{*}$. Hence, for a normal driver we have

$$
u_{0}=u_{N} \sum_{\theta=1}^{\infty} \eta_{1}\left(1-\eta_{1}\right)^{\theta-1} e^{-\theta r T}
$$

which gives

$$
u_{0}=\sigma_{1}(T) u_{N}
$$

with

$$
\sigma_{e}(T) \equiv \frac{\eta_{e} e^{-r T}}{1-\left(1-\eta_{e}\right) e^{-r T}} \text { for } e=0 \text { or } 1 .
$$

\footnotetext{
${ }^{4}$ The analogy with asset valuation methods is highlighting: The point-record licence may be viewed as an asset with current value $u$ which yields an instantaneous revenue $r u$, comprised of dividends, $\bar{v}-k$, and the expected change in the asset's value $E[d u]$.
} 
Equation (2) together with (4) allows us to determine the utility of normal drivers depending of their records. These utility levels are given in the following result and are depicted in Figure 1.

Lemma 1. The utility of a n-point normal driver always exerting effort $e=1$ is given by

$$
u_{n}=\frac{\bar{v}-k}{r}\left[1-b^{n} \frac{1-\sigma_{1}(T)}{1-b^{N} \sigma_{1}(T)}\right]
$$

where $b \equiv p_{1} /\left(r+p_{1}\right)<1$.

As intuition suggests, the driver's utility given by (5) increases with her point-record. The negative part of the bracketed term in (5) captures the effect of the point-record system. Were drivers allowed to drive every period whatever their records, careful drivers would have a discounted utility of $(\bar{v}-k) / r$. This is the case when $n$ goes to infinity in (5). With the pointrecord system, this utility level is reduced due to the fact that the driver will eventually be deprived of her licence. This prospect depends on her record though, and is more acute the lower the credit.

A point-record mechanism is said to be effective if it is (weakly) optimal for a normal driver to choose $e=1$ whatever her record (i.e. for all $n=$ $1,2, \ldots, N)$. Consider the expected utility $\tilde{u}_{n}(\varepsilon)$ of a $n$-point driver who chooses not to exert any effort during the time interval $[0, \varepsilon], \varepsilon>0$ (as long as she's not caught committing an infringement during this period) and then to drive safely for the rest of her life. It is given by

$\tilde{u}_{n}(\varepsilon)=\int_{0}^{\varepsilon} p_{0} e^{-p_{0} \tau}\left(\int_{0}^{\tau} \bar{v} e^{-r t} d t+e^{-r \tau} u_{n-1}\right) d \tau+e^{-p_{0} \varepsilon}\left(\int_{0}^{\varepsilon} \bar{v} e^{-r t} d t+e^{-r \varepsilon} u_{n}\right)$

where the first term corresponds to her expected utility in case she is caught at any date $0 \leq \tau \leq \varepsilon$ and loses one point, while the second is her expected utility if she's not caught during period $\varepsilon$. Integrating (6) gives

$$
\tilde{u}_{n}(\varepsilon)=u_{n}-\left[1-e^{-\left(p_{0}+r\right) \varepsilon}\right] \frac{r u_{n}-\bar{v}+p_{0}\left(u_{n}-u_{n-1}\right)}{p_{0}+r}
$$

The point-record mechanism is effective if $u_{n} \geq \tilde{u}_{n}(\varepsilon)$ for all $n=1,2, \ldots, N$ and all $\varepsilon \geq 0$. This is the case if the last term of (7) is positive for all $\varepsilon>0$, which, using (3), leads to the condition

$$
\bar{v}-k-p_{1}\left(u_{n}-u_{n-1}\right) \geq \bar{v}-p_{0}\left(u_{n}-u_{n-1}\right)
$$


for all $n=1,2, \ldots, N$. Interpretation of (8) is straightforward: multiplying both sides by $d t>0$, the left-hand side corresponds to $r u_{n} d t$ which is the utility reward over the time interval $[0, d t]$ for a $n$-points normal driver who makes effort any time, while the right hand side is her utility gain if she deviates during $[0, d t]$ and reverts to careful driving in the following periods. Rearranging terms allows us to rewrite (8) as

$$
u_{n}-u_{n-1} \geq \frac{k}{p_{0}-p_{1}}
$$

Using (5), one checks easily that $u_{n}-u_{n-1}$ decreases as $n$ increases. The point-record mechanism is thus effective if normal drivers with fresh records (i.e. with $n=N$ ) are induced to drive carefully. This leads to the following incentive compatibility condition

$$
\frac{\bar{v}-k}{k} \frac{p_{0}-p_{1}}{p_{1}} \geq \frac{\left(1+r / p_{1}\right)^{N}-\sigma_{1}(T)}{1-\sigma_{1}(T)} \equiv \psi(N, T)
$$

with $\psi_{N}^{\prime}>0$ and $\psi_{T}^{\prime}<0$. As expected, the greater the number of offences before the revocation of the licence, the harder it is to maintain incentives for careful driving, while increasing the length of the punishment period increases the incentive power of the point-record mechanism. We assume

$$
\frac{\bar{v}-k}{k} \frac{p_{0}-p_{1}}{p_{1}} \geq 1+r / p_{1}=\psi(1,+\infty)
$$

In words, normal drivers are deterred to infringe road regulation if they are deprived of their licence after the first offence and they cannot be reinstated.

\subsection{Welfare analysis}

The social welfare is defined as the sum of expected life-time utility over the whole population net of the external costs and external benefits of driving. These costs and benefits include the outlays for private insurance and social security which are related to the frequency and the gravity of accidents and injuries, as well as the costs of emergency services, the additional time travel spent by the other motorists, the workplace disruptions and the cost of legal proceedings in case of an accident. The difference between private and social costs of driving also arises from the difference between the private value of life (which can be measured by the drivers' willingness to pay to avoid the risks that will result in one less death) and the social value of life which reflects the marginal productivity of labor as well as the external productive 
effects entailed by the premature death of a skilled worker. External benefits also include the effect of individuals' mobility on productivity as well as on the private welfare of other individuals. The net external costs of incapacitating a driver is presumably positive, because of the induced effects on the productive system of the lower mobility of suspended drivers, although less mileage also entails external benefits due to the decrease in road congestion or to the reduction in pollution. ${ }^{5}$ To complete the definition of the social costs and benefits of driving, we must also include the licence examination cost.

As shown in the appendix and stated formally in the following lemma, it is possible to derive a rather simple expression of the social welfare at steady states reflecting all these costs and benefits, assuming that there is a constant proportion $\lambda$ of reckless drivers in the population, $0<\lambda<1$. Steady states are characterized by the $q_{e}$ proportion of type- $e$ individuals who are allowed to drive, i.e. who have at least one point, which depends on the driving licence system implemented by the Government.

Lemma 2. At steady states, the social welfare is given by

$$
W=\lambda\left[q_{0} w_{0}+\left(1-q_{0}\right)(\bar{w}-c / T)\right]+(1-\lambda)\left[q_{1} w_{1}+\left(1-q_{1}\right)(\bar{w}-c / T)\right]
$$

where $w_{0}, w_{1}$ and $\bar{w}$ denote the discounted social surplus corresponding to reckless driving, cautious driving and to the deprivation of the driving licence respectively, and where c corresponds to the per applicant discounted cost of licence examination.

The bracketed terms in (12) correspond to the expected social surplus for each type, given the proportions of active and inactive drivers. For the time being, we only consider effective point-record mechanisms, but we will show in a following section that they are indeed socially optimal. With such mechanisms, the effort level of normal drivers does not depend on $n$ : it is equal to $e=1$ for all $n=1, \ldots, N$. At steady states, normal drivers and reckless drivers are evenly distributed among the $N$ categories of active drivers. We thus have

$$
p_{e} q_{e} / N=\left(1-q_{e}\right) \eta_{e} / T \text { for } e=0,1 .
$$

Indeed, during a period of length $d t$, a $\eta_{e} d t / T$ fraction of the suspended type-e drivers pass examinations, while $p_{e} d t$ type- $e$ drivers belonging to

\footnotetext{
${ }^{5}$ On externalities in the economics of road safety, see Boyer and Dionne (1987).
} 
the 1-point record category, a $1 / N$ fraction of the active type- $e$ drivers, are caught violating driving rules and are thus deprived of their licences. Hence, with an effective point-record mechanism, the proportion of type- $e$ individuals who are allowed to drive is given by

$$
q_{e}=\frac{1}{1+p_{e} T / \eta_{e} N}
$$

Using (14), we can write the social welfare as a function of $N$ and $T$ :

$$
W(N, T)=\lambda \frac{w_{0}-\bar{w}+c / T}{1+p_{0} T / \eta_{0} N}+(1-\lambda) \frac{w_{1}-\bar{w}+c / T}{1+p_{1} T / \eta_{1} N}+\bar{w}-c / T
$$

The optimal effective driver-record mechanism maximizes $W(N, T)$ given by (15) with respect to $N$ in $\{1,2, \ldots\}$ and $T \geq 0$ subject to (10). We shall characterize the optimal driving licence system under the following assumptions

H 1. $w_{0}<\bar{w}<w_{1}$.

H 2. $\lambda w_{0}+(1-\lambda) w_{1}>\bar{w}$.

H 3. $c<\bar{T}\left(\bar{w}-w_{0}\right)$ where $\bar{T}=\sigma_{1}^{-1}\left(1-\frac{k r}{\bar{v}\left(p_{0}-p_{1}\right)-k p_{0}}\right)$.

In words, $\mathrm{H} 1$ states that reckless driving is a bad for society that entails net social costs $\bar{w}-w_{0}$ while careful driving is a good, with corresponding social surplus $w_{1}-\bar{w}$. H2 means that the proportion of reckless drivers is small enough for generalized driving prohibition to be a suboptimal policy. It can be equivalently written as $\lambda<\hat{\lambda} \equiv\left(w_{1}-\bar{w}\right) /\left(w_{1}-w_{0}\right)$. Time period $\bar{T}$ specified in H3 is deduced from binding (10) for $N=1 .^{6}$ For any effective mechanism, we have $T \geq \bar{T}$. Hence, H3 implies $w_{0}-\bar{w}+c / T<0$ for any effective mechanism, which insures that social welfare always increases when the number of reckless drivers decreases. ${ }^{7}$ Under these assumptions, it is possible to show that

Proposition 1. There exists an optimal effective point-record mechanism $(N, T)$ when $c$ is lower than a threshold $\hat{c}>0$. It is such that

$$
\psi(N+1, T)>\frac{\bar{v}-k}{k} \frac{p_{0}-p_{1}}{p_{1}} \geq \psi(N, T)
$$

\footnotetext{
${ }^{6}$ We thus have $\psi(1, \bar{T})=(\bar{v}-k)\left(p_{0}-p_{1}\right) / k p_{1}$. Using (11) and the definition of $\sigma_{1}(T)$ shows that $\bar{T}$ exists and is uniquely defined.

${ }^{7}$ If $c$ were very large, it would be preferable to increase the steady state proportion of reckless individuals allowed to drive in order to reduce the examination costs. H3 is just a convenient way to eliminate this uninteresting case.
} 
Proposition 1 says that there exists an optimal effective point-record mechanism $(N, T)$ when the examination cost is not too large. It also says that $(N+1, T)$ is not effective. In other words, $N$ is the largest number of points for which normal drivers decide to make effort, given that the length of the deprivation period is $T$. The intuition of these results is the following. Let us first observe that $W(N, T)$ only depends on $N / T$ when $c=0$ : in that case, unconstrained maximization of $W$ gives $N / T=x^{*}$. Indeed from (14), at a steady state, the number of individuals allowed to drive increases with $N / T$. However, while the government wishes to increase the number of normal drivers (by increasing $N / T$ ), it would like to reduce the number of reckless drivers (and thus decrease $N / T$ ). Consequently, a marginal increase in $N / T$ entails a marginal social benefit associated to the increased number of normal drivers, but also a marginal social cost due to the increase in the number of reckless drivers. This trade off leads to the optimal solution $N / T=x^{*}$. When $c=0$, all effective mechanisms that satisfy (10) and $N / T=x^{*}$ are optimal. This indeterminacy of the optimal mechanism clears up when $c>0$. Indeed, in that case, increasing $N$ and $T$ keeping $N / T$ unchanged reduces the frequency of examinations (and thus the per driver examination costs $c / T$ decreases), while maintaining the same number of active drivers for each type. This enhances the social welfare. However, because of the time discounting, drivers are more severely penalized by an increase in the deprivation period when $T$ is low than when it is large. Consequently when (10) is binding incentive compatibility requires that $N / T$ decreases when $T$ increases. The optimal mechanism trades off the disadvantages of moving away from $N / T=x^{*}$ and the advantages of reducing the examination costs when $T$ is increasing. When $c$ is not too large, it is suboptimal to increase indefinitely $T$ and there exists an optimal mechanism $(N, T)$, with $T$ finite.

\subsection{Optimality of effective mechanisms}

The result of the previous section is established under the assumption that effective point-record mechanisms are socially optimal. We show in this section that this is actually the case if $c$ is not too large. In fact, with non-effective point-record systems, normal drivers adopt a "trigger strategy" which consists in exerting no effort as long as their point-credit is larger than a threshold level $N^{*}$, then driving carefully. Such a behavior ultimately results in an increase in dangerous driving and produces no welfare gain unless examinations are prohibitively costly. The government should thus avoid to give a too large point allowance to drivers. We demonstrate formally 
this statement in the following two propositions. We first establish that normal drivers play a trigger strategy. We then demonstrate that any noneffective mechanism is dominated by an effective point-record mechanism.

We first proceed by generalizing our approach to mechanisms that may not be effective. The lifetime discounted expected utility of a normal driver with $n$ points is given by (1) for effective mechanism, but more generally we have

$$
\begin{gathered}
u_{n}=\max \left\{\int_{0}^{+\infty} p_{1} e^{-p_{1} \tau}\left(\int_{0}^{\tau}(\bar{v}-k) e^{-r t} d t+e^{-r \tau} u_{n-1}\right) d \tau,\right. \\
\left.\int_{0}^{+\infty} p_{0} e^{-p_{0} \tau}\left(\int_{0}^{\tau} \bar{v} e^{-r t} d t+e^{-r \tau} u_{n-1}\right) d \tau\right\}
\end{gathered}
$$

which simplifies to

$$
r u_{n}=\bar{v}-p_{1}\left(u_{n}-u_{n-1}\right)-\min \left\{k,\left(p_{0}-p_{1}\right)\left(u_{n}-u_{n-1}\right)\right\}
$$

upon integrating. With an effective mechanism, the incentive condition (9) ensures that the cost of exerting effort, $k$, is lower that the cost of careless driving in terms of expected lifetime utility loss, $\left(p_{0}-p_{1}\right)\left(u_{n}-u_{n-1}\right)$. More generally, a normal driver may adopt a state-dependent mixed strategy. Denote by $s_{n}, 0 \leq s_{n} \leq 1$ the probability for a $n$-point normal driver to choose $e=1$. Given $u_{0}$, equation (17) defines the sequence $u_{n}$ recursively as

$$
u_{n}=\left\{\begin{array}{cl}
\frac{\bar{v}-k+p_{1} u_{n-1}}{r+p_{1}} & \text { if } u_{n-1}<\widetilde{u} \\
\frac{\bar{v}+p_{0} u_{n-1}}{r+p_{0}} & \text { if } u_{n-1} \geq \widetilde{u}
\end{array}\right.
$$

where

$$
\widetilde{u}=\frac{\bar{v}}{r}-\frac{k\left(r+p_{0}\right)}{r\left(p_{0}-p_{1}\right)} .
$$

Normal drivers reach utility levels $(18)$ by using the strategy $s_{n}=1$ for $u_{n-1}<\widetilde{u}, 0 \leq s_{n} \leq 1$ for $u_{n-1}=\widetilde{u}$ and $s_{n}=0$ for $u_{n-1}>\widetilde{u}$. With a non-effective point-record mechanism $(N, T)$, there exists $n$ in $\{1, \ldots, N\}$ such that $s_{n}=0$ is the only equilibrium strategy. Proposition 2 states that normal drivers play a trigger strategy.

Proposition 2. For any point-record mechanism $(N, T)$ and any corresponding equilibrium $\left(s_{1}, \ldots, s_{N}\right)$, there exists $N^{*}$ in $\{1, \ldots, N\}$ such that $s_{n}=1$ for $1 \leq n \leq N^{*}-1,0 \leq s_{n} \leq 1$ for $n=N^{*}$ and $s_{n}=0$ for $N^{*}+1 \leq n \leq N$. 
Trigger strategies are thus optimal for normal drivers. They consist in exerting no effort as long as the point-credit is larger than the threshold level $N^{*}$, playing a mixed strategy at $n=N^{*}$ and then driving carefully when $n$ is less than $N^{*}$. Effective mechanisms correspond to the case $N=N^{*}$. The next proposition establishes that effective mechanisms are socially optimal.

Proposition 3. Any non-effective point-record mechanism is strictly dominated by an effective point-record mechanism.

\subsection{Authorities commitment}

An important problem for the enforcement of point-record mechanisms arises because the authorities may be tempted to deviate from their pre-announced strategy. More explicitly, we have postulated that reckless driving entails a cost to society and that careful driving is socially beneficial. This assumption was expressed through the inequalities $w_{0}<\bar{w}<w_{1}$. At a given time, if the population of individuals who have just lost their last point includes a large proportion of type- 1 drivers, then the authorities will have a short term incentive not to enforce the rule and in fact not to deprive the drivers of their licence. In what follows, we will show that this forbearance problem is actually endemic when the population includes a small proportion of type- 0 drivers, i.e. when $\lambda$ is small.

Denote by $\rho_{e}$ the probability that an individual who has just lost her last point is a type- $e$ driver. Bayes law gives

$$
\rho_{0}=\frac{\lambda p_{0} q_{0}}{\lambda p_{0} q_{0}+(1-\lambda) p_{1} q_{1}}
$$

and

$$
\rho_{1}=\frac{(1-\lambda) p_{1} q_{1}}{\lambda p_{0} q_{0}+(1-\lambda) p_{1} q_{1}} .
$$

Consider a particular driver in this population of individuals who have just lost their last point. Not revocating the driving licence of this individual entails a positive expected social surplus if

$$
\rho_{1}\left(w_{1}-\bar{w}\right)-\rho_{0}\left(\bar{w}-w_{0}\right)>0
$$

which, using (19) and (20), is equivalently expressed as $\lambda<\lambda_{s}$ where

$$
\begin{aligned}
\lambda_{s} & =\frac{p_{1} q_{1}\left(w_{1}-\bar{w}\right)}{p_{1} q_{1}\left(w_{1}-\bar{w}\right)+p_{0} q_{0}\left(\bar{w}-w_{0}\right)} \\
& >\frac{p_{1}\left(w_{1}-\bar{w}\right)}{p_{1}\left(w_{1}-\bar{w}\right)+p_{0}\left(\bar{w}-w_{0}\right)}
\end{aligned}
$$


using $q_{1}>q_{0}$. When the proportion of reckless drivers is lower than $\lambda_{s}$, the lack of credibility may jeopardize the enforcement of the optimal pointrecord mechanism since the authorities are tempted to be too clement in the application of the law. In other words, the forbearance problem is particularly acute when reckless drivers are concentrated in a small, but dangerous, subset of the population. The lower bound on $\lambda_{s}$ suggests that the inequality $\lambda<\lambda_{s}$ may well be satisfied in practice, so that forbearance is not a purely theoretical consideration. Assume for instance (just for illustrative purposes) that $p_{0}=5 p_{1}$ and $\bar{w}-w_{0}=w_{1}-\bar{w}$, i.e. the probability of losing a point per unit of time is five times larger for a reckless driver than for a normal driver, with the social cost of reckless driving being equal to the social surplus of normal driving. Then $\lambda_{s}$ is larger than 0.166. In such a case, if the reckless drivers amount to, say, $10 \%$ of the total population, then the authorities would have an incentive to deviate from the optimal mechanism.

This commitment problem gives legitimacy to procedures (such as the one recently implemented in France) where the loss of the last point entails the cancelling of the driving licence automatically, without any additional appraisal of the pros and cons of this decision for a particular driver. In other words, for the sake of credibility, the authorities in charge of the enforcement of the point-record mechanism should not be given the possibility to appraise the desirability of the cancelling of a driving licence, given the available information about the past history of the driver (e.g. whether she has been previously involved in an accident or whether the cancelling of the driving licence may lead the individual to lose her job). Automaticity of the mechanism should be the rule. The following Proposition summarizes these results.

Proposition 4. The enforcement of the optimal point-record mechanism requires a commitment of the authorities when $\lambda<\lambda_{s}$. In that case, the Government should use automatic licence cancelling procedures in order to commit to cancel the driving licence of the individuals who lose their last point.

\section{More general point-record mechanisms}

In this section, we first extend our approach to analyze "redemptive" systems, where drivers can redeem points if they are not indicted during a given duration. We show that redemptive point-record licences allow for a better screening of individuals. Indeed, regaining points is more difficult for reckless drivers than for sane individuals. We then turn to probationary licences, 
a special feature for new drivers. With these systems, new drivers have to demonstrate their ability to drive during a probationary period before being granted a full credit of points. This transient phase helps the authorities to discriminate between dangerous and normal drivers. It may be completed with a reduced-credit licence for beginners who fail to cross the transient phase without indictment. We analyze such systems, and demonstrate that they increase the social welfare.

\subsection{Redemptive mechanisms}

This section is devoted to systems where drivers are reinstated with a fresh record after a time-period of length $M$ without driving offence. Let $u_{n}(t)$ be the expected utility of a normal driver who has got $n$ points for a time $t$. The redemption feature of the system implies that $u_{n}(M)=u_{N}$ for all $n \in\{1, \ldots, N-1\}$. For a driver whose point-record is equal to $n<N$ since a time-period $t<M$, we thus have

$$
\begin{aligned}
u_{n}(t) & =\int_{0}^{M-t} p_{1} e^{-p_{1} \tau}\left(\int_{0}^{\tau}(\bar{v}-k) e^{-r t^{\prime}} d t^{\prime}+u_{n-1}^{0} e^{-r \tau}\right) d \tau \\
& +e^{-p_{1}(M-t)}\left(\int_{0}^{M-t}(\bar{v}-k) e^{-r t^{\prime}} d t^{\prime}+e^{-r(M-t)} u_{N}\right)
\end{aligned}
$$

where $u_{n-1}^{0} \equiv u_{n-1}(0)$ denotes the utility of a driver who has just been indicted and whose record, previously equal to $n$, has thus just been decreased from one point. The first term of (22) corresponds to the driver's expected utility in case she's caught committing an infringement during the redemption period while the second term is the utility she enjoys if she crosses the period without committing an offence. Computing the integrals in (22) gives

$$
u_{n}(t)=\frac{\bar{v}-k+p_{1} u_{n-1}^{0}}{r+p_{1}} \gamma(M-t)+[1-\gamma(M-t)] u_{N}
$$

where

$$
\gamma(t) \equiv 1-e^{-\left(r+p_{1}\right) t}
$$

Observe that contrary to the previous section, the expected lifetime utility of a $n$-point record driver with $n<N$ evolves over time. (23) defines a recursive equation between lifetime utilities of drivers who have just been indicted (i.e., for whom $t=0$ ) for all $n \in\{1, \ldots, N-1\}$. In other words, for $t=0,(23)$ gives $u_{n}^{0}$ as a function of $u_{n-1}^{0}$ and $u_{N}$. Using $u_{0}^{0}=\sigma_{1}(T) u_{N}$ allows us to solve this recursive equation. 
Lemma 3. The expected utility $u_{n}(t)$ of a driver who has got $n$ points for a period of length $t$, with $t<M$, is given by (23) where

$$
u_{n}^{0}=\frac{a \gamma(M)\left[1-\sigma_{1}(T) b^{N} \gamma(M)^{N}-b^{n} \gamma(M)^{n}\left(1-\sigma_{1}(T)\right)\right]}{[1-b \gamma(M)]\left[1-b^{N} \gamma(M)^{N} \sigma_{1}(T)\right]-[1-\gamma(M)]\left[1-b^{N} \gamma(M)^{N}\right]}
$$

for all $n \in\{1, \ldots, N\}$, with $a \equiv(\bar{v}-k) /\left(r+p_{1}\right), b \equiv p_{1} /\left(r+p_{1}\right)$ and $u_{0}^{0}=\sigma_{1}(T) u_{N} \cdot u_{n}(t)$ increases with $n$ for all $t \leq M$ and $u_{n}^{\prime}(t)>0$ for all $t<M$.

Not surprisingly, the driver's utility increases over time within a category and is greater the larger the point-record. As $\gamma(+\infty)=1$, (25) converges to (5) as $M \rightarrow+\infty$.

Focusing on effective point-record systems, it must be the case that $u_{n}(t) \geq \tilde{u}_{n}(t, \varepsilon)$ for all $t<M, \varepsilon>0$ and $n \leq N$, where $\tilde{u}_{n}(t, \varepsilon)$ corresponds to the expected utility of a driver who decides to not exert any effort during period $[0, \varepsilon]$ with $\varepsilon<M-t$, provided she is not indicted. We have

$$
\begin{aligned}
\tilde{u}_{n}(t, \varepsilon) & =\int_{0}^{\varepsilon} p_{0} e^{-p_{0} \tau}\left(\int_{0}^{\tau} \bar{v} e^{-r t^{\prime}} d t^{\prime}+e^{-r \tau} u_{n-1}^{0}\right) d \tau \\
& +e^{-p_{0} \varepsilon}\left(\int_{0}^{\varepsilon} \bar{v} e^{-r t^{\prime}} d t^{\prime}+e^{-r \varepsilon} u_{n}(t+\varepsilon)\right)
\end{aligned}
$$

which has the same interpretation as (6) and simplifies to

$$
\tilde{u}_{n}(t, \varepsilon)=u_{n}(t+\varepsilon)-\left[1-e^{-\left(p_{0}+r\right) \varepsilon}\right] \frac{r u_{n}(t+\varepsilon)-\bar{v}+p_{0}\left[u_{n}(t+\varepsilon)-u_{n-1}^{0}\right]}{p_{0}+r}
$$

Since $\tilde{u}_{n}(t, 0)=u_{n}(t)$, a necessary condition for the point-record mechanism to be effective is given by $\left.\frac{\partial \tilde{u}_{n}(t, \varepsilon)}{\partial \varepsilon}\right|_{\varepsilon=0} \leq 0$ or equivalently

$$
r u_{n}(t) \geq \bar{v}-p_{0}\left[u_{n}(t)-u_{n-1}^{0}\right]+u_{n}^{\prime}(t) \text { for all } n \text { and all } t<M .
$$

Under (26), we have $\partial \tilde{u}_{n}(t, \varepsilon) / \partial \varepsilon \leq 0$ if $0 \leq \varepsilon \leq M-t$. (26) is thus a necessary and sufficient effectiveness condition. Differentiating (23) gives

$$
r u_{n}(t)=\bar{v}-k-p_{1}\left[u_{n}(t)-u_{n-1}^{0}\right]+u_{n}^{\prime}(t)
$$

for all $n$. Hence, (26) simplifies to

$$
u_{n}(t)-u_{n-1}^{0} \geq k /\left(p_{0}-p_{1}\right)
$$


which must be satisfied for all $n \leq N$ and all $t \leq M$. Since $u_{n}(t)$ increases with $t,(27)$ reduces to

$$
u_{n}^{0}-u_{n-1}^{0} \geq k /\left(p_{0}-p_{1}\right)
$$

for all $n \leq N$. Using (25), one checks that $u_{n}^{0}-u_{n-1}^{0}$ decreases with $n$. Consequently, (27) holds for all $n$ and $t$ provided that it holds for $n=N$ and $t=0$ which leads to the condition

$\frac{\bar{v}-k}{k} \frac{p_{0}-p_{1}}{p_{1}} \geq \frac{\gamma(M)^{-N}\left(1+r / p_{1}\right)^{N}-\sigma_{1}(T)}{1-\sigma_{1}(T)}-\frac{[1-\gamma(M)]\left[b^{-N} \gamma(M)^{-N}-1\right]}{[1-b \gamma(M)]\left(1-e^{-r T}\right)}$

which is the extension of (10) to the case of redemptive mechanisms. As $\gamma(+\infty)=1$, the right hand side of (28) converges to $\psi(N, T)$ as $M \rightarrow+\infty$.

To perform the welfare analysis, we also have to determine the $q_{e}$ proportions of type- $e$ drivers entitled to drive. Here also we restrict attention to steady states. However, compared to non-redemptive systems, drivers records are not evenly distributed among the $N$ categories of active drivers, and (13) does not hold. The steady state proportions are derived as follows. Since the same reasoning applies for each drivers' type, neglect drivers' types for the moment and remove subscript $e$. Denote by $q$ the steady state proportion of active drivers of the type considered and by $q_{n}(t) d t$ the proportion of active drivers who have been in the $n$ points category for a length of time $t^{\prime} \in[t, t+d t]$, with $q_{n}^{0}=q_{n}(0)$ and $q_{n}(t)=q_{n}^{0} e^{-p t}$. At a steady state, we have $q_{n-1}^{0}=q_{n}^{0}\left(1-e^{-p M}\right)$ for all $n=1, \ldots, N-1$ and $q_{N-1}^{0}=q_{N}^{0}$ which gives $^{8}$

$$
q_{n}^{0}=q_{N}^{0}\left(1-e^{-p M}\right)^{N-1-n} \quad \text { for all } n=1, \ldots, N-1 .
$$

We may write

$$
q_{N}^{0}=(1-q) \eta / T+\sum_{n=1}^{N-1} q_{n}(M)
$$

with $\eta=\eta_{0}$ or $\eta_{1}$ according to the drivers' type, since in addition to the $\eta / T$ fraction of the suspended $1-q$ drivers who pass examinations, all drivers lucky enough to not have been convicted during the redemption period get a fresh record.

\footnotetext{
${ }^{8}$ Indeed for all $n=1, \ldots, N-1$, a proportion $1-e^{-p M}$ of $n$-point drivers will ultimately join the $(n-1)$-point group, while the other ones will redeem a fresh record. Similarly, all $N$-point drivers will ultimately join the $(N-1)$-point group.
} 
Finally, the total proportion of individuals (of a given type) allowed to drive is given by

$$
q=\sum_{n=1}^{N-1} \int_{0}^{M} q_{n}(t) d t+\int_{0}^{\infty} q_{N}(t) d t
$$

which, after some straightforward computations involving (29) and (30), gives the following result

Lemma 4. The $q_{e}$ fraction of active type-e drivers is given by

$$
q_{e}=\frac{1}{1+y\left(N, e^{-p_{e} M}\right) p_{e} T / \eta_{e}}
$$

where

$$
y(N, x) \equiv \frac{(1-x)^{N-1} x}{1-(1-x)^{N}}
$$

with $\partial y / \partial x<0$ and $y(N, 0)=1 / N$.

As intuition suggests, since $\partial y / \partial x<0$ the proportion of active drivers increases when the length of the redemption period decreases. Intuition also suggests that non-redemptive systems are peculiar cases of redemptive ones, when the required period to redeem points is infinitely long. As $y(N, x) \rightarrow$ $1 / N$ when $x \rightarrow 0$, this is effectively the case since $q_{e}$ given by (32) coincides with (14) when $M$ goes to infinity.

The optimal effective point-record mechanism $\left(N^{*}, T^{*}, M^{*}\right)$ maximizes the social welfare (12) with respect to $N, T$ and $M$, with proportions of licenced drivers given by (32) for $e=0$ and 1, subject to the incentive constraint (28). A non-redemptive system would be optimal if choosing $M$ infinitely large were optimal. The following proposition shows that this is not the case.

Proposition 5. The optimal driver-record system is redemptive, i.e. $M^{*} \ll$ $+\infty$.

Redemptive mechanisms are optimal because they act as a screening device. Indeed, it is more difficult for reckless drivers to redeem points than for normal individuals. A redemptive clause reduces the incentive power of the point-record mechanism, but this effect may be compensated by an increase in $T$ or a decrease in $N$. In particular, when $M$ is very large but finite, incentives can be preserved through a small increase in $T$. Starting 
from an optimal non-redemptive mechanism (i.e. $M=+\infty$ ), such a small increase in $T$ entails a second-order effect on welfare, while the screening effect of the redemption clause is first-order. On the whole, the scales are tipped in favour of the redemptive mechanism.

\subsection{Probationary licences}

We now complete the analysis by introducing the renewal of the population and complementing the regulation with probationary drivers' licence systems. For simplicity, we only consider non-redemptive systems in this section.

Assume that the population is renewed over time at rate $\pi$, and that new drivers are given a temporary allowance to drive during period $L$. Over this transient phase, they have to demonstrate that they deserve to be entitled a normal licence $(N, T)$ by not defaulting driving rules. Should they be convicted during this time, they will have a specific licence for the rest of their lives with $R$ points and a deprivation period $T^{\prime}$, beginning by $R-1$ points at the time they are caught defaulting. We thus consider two possible driving licences: $(N, T)$ or $\left(R, T^{\prime}\right)$.

Let $u(\ell)$ denote the expected utility of a $\ell$-old normal driver, (with $\ell<L$ ) who has never been convicted so far. Let also $\hat{u}_{r}$ denote the expected utility of a normal driver who was convicted during the probationary period she thus has at most $R$ points - and who has a $r$-point record (with $r \in$ $\{0, \ldots, R\}) . \hat{u}_{r}$ is deduced from (5) by substituting $R$ to $N, T^{\prime}$ to $T$ and $r$ to $n$. For a young driver, we have ${ }^{9}$

$$
\begin{aligned}
u(\ell) & =\int_{0}^{L-\ell} p_{1} e^{-p_{1} \tau}\left(\int_{0}^{\tau}(v-k) e^{-r t^{\prime}} d t^{\prime}+\hat{u}_{R-1} e^{-r \tau}\right) d \tau \\
& +e^{-p_{1}(L-\ell)}\left(\int_{0}^{L-\ell}(v-k) e^{-r t^{\prime}} d t^{\prime}+u_{N} e^{-r(L-\ell)}\right)
\end{aligned}
$$

for all $\ell<L$. Since the driver gets a normal licence with $N$ points if she has not been convicted during her probationary period, we also have $u(L)=u_{N}$. Integrating (33) and using the fact that $\hat{u}_{r}$ satisfies an equation similar to (2) for all $r \leq R$ gives

$$
u(\ell)=u_{N}-\gamma(L-\ell)\left(u_{N}-\hat{u}_{R}\right)
$$

\footnotetext{
${ }^{9}$ Compared to the previous sections, the relevant discount rate accounts for the probability of death, i.e. $r=\hat{r}+\pi$ where $\hat{r}$ denotes the psychological discount rate of an individual who never dies.
} 
The expected utility of a novice is thus equal to a $N$-point experienced driver's utility diminished by the expected loss of being convicted during (the rest of) the probationary period. This utility increases over time during the probationary period, i.e. we have $u^{\prime}(\ell)>0$ for all $\ell<L$.

A record system with a probationary period is effective if, in addition to satisfy $(10)$ for $(N, T)$ and $\left(R, T^{\prime}\right)$, it also induces new drivers to exert an effort before they get their final licence. Using developments that parallel those exposed in the previous section allows us to show that effectiveness requires

$$
\bar{v}-k-p_{1}\left[u(\ell)-\hat{u}_{R-1}\right]+u^{\prime}(\ell) \geq \bar{v}-p_{0}\left[u(\ell)-\hat{u}_{R-1}\right]+u^{\prime}(\ell)
$$

for all $\ell<L$. Rearranging terms and using the fact that $u(\ell)$ is increasing leads to

$$
u(0)-\hat{u}_{R-1} \geq k /\left(p_{0}-p_{1}\right)
$$

The following lemma establishes that new normal drivers choose to drive carefully when old normal drivers do so.

Lemma 5. Condition (35) is satisfied whenever the $\left(R, T^{\prime}\right)$ point-record licence system is effective.

To perform the welfare analysis, we have to determine the $q_{e}$ proportions of type-e drivers entitled to drive. Because of the renewal of the population, drivers records are not evenly distributed among the different categories of active drivers and (13) does not apply. Let $q_{n}^{e}$ and $\hat{q}_{r}^{e}$ denote the proportions of (experienced) type- $e$ active drivers whose records belong to the $n$ points category (among $N$ ) or to the $r$ points category (among $R$ ) respectively. Let also $\widetilde{q}^{e}(\ell) d \ell$ be the proportion of $t$-old type- $e$ drivers who have never been convicted, with $t \in[\ell, \ell+d \ell]$ and $0 \leq \ell \leq L$. We have

$$
q_{e}=\int_{0}^{L} \widetilde{q}^{e}(\ell) d \ell+\sum_{n=1}^{N} q_{n}^{e}+\sum_{r=1}^{R} \hat{q}_{r}^{e}
$$

i.e., active drivers are either new drivers in their probationary phases, or older drivers with a strictly positive record belonging to one of the two licence' types.

Lemma 6. The proportion of active type-e drivers ( $e=0$ or 1$)$ is given by

$$
q_{e}=e^{-\left(\pi+p_{e}\right) L} \Phi\left(p_{e}, N, T\right)+\left[1-e^{-\left(\pi+p_{e}\right) L}\right] \Phi\left(p_{e}, R, T^{\prime}\right)
$$


where

$$
\begin{gathered}
\Phi\left(p_{e}, A, B\right) \equiv \frac{1-\left(\frac{p_{e}}{p_{e}+\pi}\right)^{A}}{1-\beta_{e}(B)\left(\frac{p_{e}}{p_{e}+\pi}\right)^{A}} \\
\beta_{e}(B)=\frac{\eta_{e} e^{-\pi B}}{1-\left(1-\eta_{e}\right) e^{-\pi B}}
\end{gathered}
$$

for $A=N$ or $R$ and $B=T$ or $T^{\prime}$.

The optimal effective driver-record system is determined by the values $N^{*}, R^{*}, T^{*}$ and $T^{*}$ that maximize the social welfare subject to effectiveness constraints (10) and with the proportions of active drivers given by (36).

Proposition 6. Probationary driving licences are optimal.

Here also, probationary licences increase the social welfare because they act as a screening device. The probationary period allows the government to discriminate between drivers who have or have not been caught infringing the road regulation. Indeed, Bayes law shows that the probability of a driver to be a type- 0 is larger in the first group than in the second one and consequently the driving licence should be different according to the infraction experience in the probationary period.

\section{Severe driving offences and licence deprivation}

Till now we have restricted attention to a single category of road infringements. This section extends our model to the case where driving offences are diverse in their nature and may be more or less acute depending of their intensity.

Denote by $s \in[0,1]$ the seriousness of a driving offence. $s$ is random and depends on the behavior of the driver. Conditionally on being spotted by the police for a driving offence, $s$ is distributed over $[0,1]$ according to cumulative distribution $F_{e}(s)$ and density function $f_{e}(s)=F_{e}^{\prime}(s)>0$ for all $s \in(0,1)$. Hence $F_{e}(s)$ is the probability that the seriousness of the driving offence is less than $s$ when a type-e driver is caught committing an offence. This distribution satisfies the Monotone Likelihood Ratio 
Property (MLRP), i.e. $f_{0}(s) / f_{1}(s)$ increases with $s .{ }^{10}$ Hence, the larger the seriousness of the offence, the larger the likelihood that such an offence is committed by a reckless driver $(e=0)$ relative to the likelihood that the offender is a normal driver $(e=1)$. As we will show, it may then be socially optimal to directly deprive drivers from their licences when they commit very serious driving offences. We shall investigate this possibility by considering regulations that involve two seriousness thresholds, $s^{\prime}$ and $s^{\prime \prime}$ with $0 \leq s^{\prime}<s^{\prime \prime} \leq 1$. These thresholds determine the number of points lost by a driver caught committing an infringement. When $s \in\left[0, s^{\prime}\right)$ the driver's record is unchanged, whereas it is reduced by one point if $s \in\left[s^{\prime}, s^{\prime \prime}\right)$ and set to zero for more severe infringements: the driver is thus deprived from her licence for all $s \in\left[s^{\prime \prime}, 1\right]$.

Let $\pi_{e} d t$ be the probability that a type-e driver is caught committing an offence during an infinitesimal time period of length $d t$, with $\pi_{0}>\pi_{1}>0$. $\pi_{0}$ and $\pi_{1}$ are determined by the frequency of police control. They are considered as given parameters in the present analysis. The driver loses at least one point with probability $p_{e}\left(s^{\prime}\right) d t$ where $p_{e}\left(s^{\prime}\right) \equiv \pi_{e}\left[1-F_{e}\left(s^{\prime}\right)\right]$. Denote by $\mu_{e}\left(s^{\prime}, s^{\prime \prime}\right)=\left[F_{e}\left(s^{\prime \prime}\right)-F_{e}\left(s^{\prime}\right)\right] /\left[1-F_{e}\left(s^{\prime}\right)\right]$ the probability of losing one point once convicted. A convicted type- $e$ driver with a point credit larger than 1 is directly deprived of her licence with probability $1-\mu_{e}\left(s^{\prime}, s^{\prime \prime}\right)$. We have $\mu_{e}\left(s^{\prime}, 1\right)=1$ and $\mu_{e}\left(s^{\prime}, s^{\prime \prime}\right)<1$ whenever $s^{\prime \prime}<1$.

With such a point-record mechanism, the expected utility of a $n$-point careful driver satisfies

$$
r u_{n}=\bar{v}-k-p_{1}\left[\mu_{1}\left(u_{n}-u_{n-1}\right)+\left(1-\mu_{1}\right)\left(u_{n}-u_{0}\right)\right]
$$

which differs from (3) since the driver, once convicted, may lose one point with probability $\mu_{1}$ or all her points with probability $1-\mu_{1}$. Similarly to (7), the expected utility of a $n$-point driver who chooses not to exert any effort during the time interval $[0, \varepsilon], \varepsilon>0$ is given by

$\tilde{u}_{n}(\varepsilon)=u_{n}-\left[1-e^{-\left(p_{0}+r\right) \varepsilon}\right] \frac{r u_{n}-\bar{v}+p_{0}\left[\mu_{0}\left(u_{n}-u_{n-1}\right)+\left(1-\mu_{0}\right)\left(u_{n}-u_{0}\right)\right]}{p_{0}+r}$

\footnotetext{
${ }^{10}$ In practice, driving offences may be characterized by a multidimensional random vector $Z=\left(z_{1}, z_{2}, \ldots, z_{L}\right)$. Each component $z_{h}$ of $Z$ corresponds to a specific characterization of the road infringement, say speed, alcohol level, risky driving, bad state of the car,... Following Milgrom (1981), as long as two random vectors are comparable (they either lead to equivalent posterior beliefs about the driver's effort or one is more "favorable" than the other in increasing posterior beliefs), we can find a sufficient statistic for $Z$ (that we call seriousness) with support $[0,1]$ and with densities that have strict MLRP.
} 
Using these expressions allows us to write the effectiveness condition (i.e. $\tilde{u}_{n}(\varepsilon) \leq u_{n}$ for all $\varepsilon>0$ and all $\left.n=1, \ldots, N\right)$ as

$$
\phi\left(s^{\prime}, s^{\prime \prime}, n, N, T\right) \geq \frac{k}{a\left[1-\sigma_{1}(T)\right]} \quad \text { for all } n=1, \ldots, N
$$

where

$\phi\left(s^{\prime}, s^{\prime \prime}, n, N, T\right) \equiv \frac{b^{n-1} \mu_{1}^{n-1}\left[p_{0}\left(\mu_{0}-\mu_{1} b\right)-p_{1} \mu_{1}(1-b)\right]-p_{1}\left(1-\mu_{1}\right)+p_{0}\left(1-\mu_{0}\right)}{1-b \mu_{1}-\sigma_{1}(T)\left[b\left(1-\mu_{1}\right)+b^{N} \mu_{1}^{N}(1-b)\right]}$

To investigate whether the direct revocation of driving licence is socially optimal, consider stationary equilibria. The proportion of active type- $e$ drivers satisfies $q_{n}^{e}=p_{e} \mu_{e} q_{n+1}^{e}+\left(1-p_{e}\right) q_{n}^{e}$ for $n \in\{1, \ldots, N-1\}$, since type-e drivers lose one point with probability $p_{e} \mu_{e}$ per unit of time and they are not convicted with probability $1-p_{e}$. Consequently $q_{n}^{e}=\mu_{e} q_{n+1}^{e}$ which implies $q^{e} \equiv \sum_{n=1}^{N} q_{n}^{e}=q_{N}\left(1-\mu_{e}^{N}\right) /\left(1-\mu_{e}\right)$. Moreover, at a stationary equilibrium the flow of drivers reinstated equals the number of $N$-point drivers who lose either one or all their points, i.e., we must have $\eta_{e}\left(1-q^{e}\right) / T=p_{e} q_{N}^{e}$. This condition leads to

$$
q^{e}=\frac{1}{1+p_{e} T / \eta_{e} z\left(\mu_{e}, N\right)}
$$

where

$$
z(\mu, N)=\frac{1-\mu}{1-\mu^{N}}
$$

The stationary social welfare (12) can then be written as

$$
\lambda \frac{w_{0}-\bar{w}+c / T}{1+p_{0}\left(s^{\prime}\right) T / \eta_{0} z_{0}\left(\mu_{0}\left(s^{\prime}, s^{\prime \prime}\right), N\right)}+(1-\lambda) \frac{w_{1}-\bar{w}+c / T}{1+p_{1}\left(s^{\prime}\right) T / \eta_{1} z_{0}\left(\mu_{1}\left(s^{\prime}, s^{\prime \prime}\right), N\right)}+\bar{w}-c / T
$$

ant the optimal mechanism maximizes (38) with respect to $0 \leq s^{\prime} \leq s^{\prime \prime} \leq$ $1, T \geq 0, N \in \mathbb{N}^{*}$ subject to the incentive constraints (37). It is shown in the appendix that

Proposition 7. Ceteris paribus, when $f_{0}(1) / f_{1}(1)$ is large enough, the optimal point-record mechanism is such that $s^{\prime \prime}<1$.

Proposition 7 states a sufficient condition for the optimal mechanism to be such that $s^{\prime \prime}<1$ : ceteris paribus $f_{0}(1) / f_{1}(1)$ should be large enough. ${ }^{11}$

\footnotetext{
${ }^{11}$ The lower bound of $f_{0}(1) / f_{1}(1)$ above which $s^{\prime \prime}<1$ is optimal is given in the proof of the Proposition.
} 
This is a very intuitive condition: the Government is justified in revocating the driving licence in the cases of very serious offences that are strongly informative on the driving behavior. Indeed, in such cases the advantages of incapacitating reckless drivers prevails over the disadvantages of imposing an exaggeratedly strong penalty on some normal drivers who (say in a momentary lapse of concentration) may have committed a very serious driving offence.

\section{Conclusion}

This paper has shown that point-record driving licences are beneficial for society for two reasons: They force normal drivers to drive more safely (at any time with effective mechanisms) and the removal of the licence afflicts more often reckless drivers than sane individuals. In other words, point-record mechanisms act simultaneously as a deterring device and as a screening and incapacitating device. In our model there exists an optimal point-record system, but its efficiency may be jeopardized by a forbearance problem. We also have shown that redemptive mechanisms and probationary periods are welfare improving because they strengthen the screening of drivers in a useful way. Finally, the government has good grounds for the direct revocation of driving licences in the cases of very serious offences.

Of course, this analysis has been developed in a highly simplified model and extending our results to a more realistic framework would be particularly useful. Such an extension may involve several types of driving-related offences with point endorsement on the licence according to their gravity. Some offences may be concentrated on reckless drivers (e.g. alcohol at the wheel) and others may concern a larger number of individuals (e.g. excess speed). The interaction between screening and incentives may thus be different according to the type of the offence, which affects the scale of point penalties.

Another important extension would be to study the relationship between point records and other deterring mechanisms, especially fines and insurance experience rating. Note that insurance rating may also depend on the drivers' point-record, which extends the range of the point-record as an incentive device. ${ }^{12}$

\footnotetext{
${ }^{12}$ See Dionne (2000) on the system implemented in Québec.
} 


\section{References}

[1] Blomquist, G.C. (1988), The Regulation of Motor Vehicle and Traffic Safety, Kluwer Academic Publishers.

[2] Boyer, M and G. Dionne (1987), The economics of road safety, Transportation Research, 21B(5),413-431.

[3] Dionne, G. (2000), Les "points d'inaptitudes" doivent ils être utilisés par les assureurs?, Risques, $\mathrm{N}^{\circ} 44,82-87$.

[4] Graham J.D. and S. Garber (1984), Evaluating the effects of automobile safety regulation, Journal of Policy Analysis and Management, vol. 3, No 2, 206-224.

[5] L. Kaplow, (1990), A Note on the Optimal Use of Nonmonetary Sanctions, Journal of Public Economics, 42(2), 245-47.

[6] Milgrom, P. (1981), Good News and Bad News: Representation Theorems and Applications, Bell Journal of Economics, 12(2), 380-91.

[7] Peltzman, S., (1975), The effects of automobile safety regulation, Journal of Political Economy, 83(4), 677-725.

[8] Polinsky, A. and S. Shavell (2000), The Economic Theory of Public Enforcement of Law, Journal of Economic Literature, 38(1), 45-76.

[9] S. Shavell (1987a), The Optimal Use of Nonmonetary Sanctions as a Deterrent, American Economic Review, 77(4), 584-92.

[10] S. Shavell (1987b), A Model of Optimal Incapacitation, American Economic Review, 77(2), 107-10. 


\section{Appendix}

\section{A Properties of point-records mechanisms}

\section{A.1 Proof of Lemma 1}

(2) can be written as

$$
u_{n}=a+b u_{n-1}
$$

where

$$
a \equiv \frac{\bar{v}-k}{r+p_{1}}>0
$$

and

$$
b \equiv \frac{p_{1}}{r+p_{1}}<1
$$

Solving (39) for $u_{n}$ gives

$$
u_{n}=\frac{a}{1-b}\left(1-b^{n}\right)+b^{n} u_{0}
$$

Using (39) and (4), a fresh record driver thus enjoys

$$
\begin{aligned}
u_{N} & =\frac{a}{1-b}\left(1-b^{N}\right)+b^{N} \sigma_{1}(T) u_{N} \\
& =\frac{a}{1-b} \frac{1-b^{N}}{1-b^{N} \sigma_{1}(T)},
\end{aligned}
$$

and a driver deprived of her licence gets

$$
u_{0}=\frac{a}{1-b} \frac{\alpha_{1}(T)\left(1-b^{N}\right)}{1-b^{N} \sigma_{1}(T)},
$$

which gives

$$
\begin{aligned}
u_{n} & =\frac{a}{1-b}\left[1-b^{n}\left(1-\frac{\sigma_{1}(T)\left(1-b^{N}\right)}{1-b^{N} \sigma_{1}(T)}\right)\right] \\
& =\frac{a}{1-b}\left[1-b^{n} \frac{1-\sigma_{1}(T)}{1-b^{N} \sigma_{1}(T)}\right]
\end{aligned}
$$

hence (5). 


\section{A.2 Proof of Lemma 2}

Let $E_{b}>0$ and $E_{c}>0$ denote the instantaneous net external benefits of cautious driving $(e=1)$ and the net external costs of reckless driving $(e=0)$ respectively. Denotes also by $E_{d}$ the net external costs of not being allowed to drive and by $\widetilde{c}$ the driving licence examination cost per applicant. The lifetime expected utility of a reckless driver with $n$ points, with $n \in\{1, \ldots, N\}$, can be derived following the same reasoning as in Lemma 1 and is given by

$$
u_{n}^{\prime}=\frac{\bar{v}}{r}\left[1-\left(b^{\prime}\right)^{n} \frac{1-\sigma_{0}(T)}{1-\left(b^{\prime}\right)^{N} \sigma_{0}(T)}\right]
$$

with $b^{\prime} \equiv p_{0} /\left(r+p_{0}\right)$. At steady state, the proportion of type-e drivers with $n$ points is equal to $q_{e} / N$ for all $n=1, \ldots, N$, with expected utility $u_{n}^{\prime}$ for $e=0$ and $u_{n}$ for $e=1$. The proportion of type- 1 individuals who are deprived of their licence is $1-q_{1}$. A proportion $\eta_{1}\left(1-\eta_{1}\right)^{\theta-1}$ of these individuals make the examination $\theta$ times before succeeding. The expected utility of the individuals who are deprived of their licence is thus $u_{N} \sum_{\theta=1}^{\infty} \eta_{1}\left(1-\eta_{1}\right)^{\theta-1} e^{-r(\theta T-t)}$ where $t$ denotes the time spent since she has lost her last point or she has made the examination. Among these individuals, $t$ is uniformy distributed over $[0,1]$. The same also applies for type- 0 individuals with $\eta_{0}, u_{N}^{\prime}$ instead of $\eta_{1}, u_{N}$. External effects and examination cost included, the steady state social welfare is written as

$$
\begin{aligned}
W & =\lambda\left\{q_{0}\left(\sum_{n=1}^{N} \frac{u_{n}^{\prime}}{N}-\frac{E_{c}}{r}\right)\right. \\
& \left.+\left(1-q_{0}\right)\left[u_{N}^{\prime} \sum_{\theta=1}^{\infty} \eta_{0}\left(1-\eta_{0}\right)^{\theta-1} \int_{0}^{T} \frac{1}{T} e^{-r(\theta T-t)} d t-\frac{(\widetilde{c} / T)+E_{d}}{r}\right]\right\} \\
& +(1-\lambda)\left\{q_{1}\left(\sum_{n=1}^{N} \frac{u_{n}}{N}+\frac{E_{b}}{r}\right)\right. \\
& \left.+\left(1-q_{1}\right)\left[u_{N} \sum_{\theta=1}^{\infty} \eta_{1}\left(1-\eta_{1}\right)^{\theta-1} \int_{0}^{T} \frac{1}{T} e^{-r(\theta T-t)} d t-\frac{(\widetilde{c} / T)+E_{d}}{r}\right]\right\}
\end{aligned}
$$


which after integrating, simplifies to

$$
\begin{aligned}
W & =\lambda\left\{q_{0}\left(\sum_{n=1}^{N} \frac{u_{n}^{\prime}}{N}-\frac{E_{c}}{r}\right)+\left(1-q_{0}\right)\left(\frac{\eta_{0}}{r T}\left[1-\sigma_{0}(T)\right] u_{N}^{\prime}-\frac{(\widetilde{c} / T)+E_{d}}{r}\right)\right\} \\
& +(1-\lambda)\left\{q_{1}\left(\sum_{n=1}^{N} \frac{u_{n}}{N}+\frac{E_{b}}{r}\right)+\left(1-q_{1}\right)\left(\frac{\eta_{1}}{r T}\left[1-\sigma_{1}(T)\right] u_{N}-\frac{(\widetilde{c} / T)+E_{d}}{r}\right)\right\}
\end{aligned}
$$

Using (5) and (42) leads to

$$
W=\lambda\left\{q_{0} \frac{\bar{v}-E_{c}}{r}-\left(1-q_{0}\right) \frac{(\widetilde{c} / T)+E_{d}}{r}\right\}+(1-\lambda)\left\{q_{1} \frac{\bar{v}-k+E_{b}}{r}-\left(1-q_{1}\right) \frac{(\widetilde{c} / T)+E_{d}}{r}\right\}
$$

Defining $w_{0}=\left(\bar{v}-E_{c}\right) / r, w_{1}=\left(\bar{v}-k+E_{b}\right) / r, \bar{w}=-E_{d} / r$ and $c=\widetilde{c} / r$ gives (12).

\section{A.3 Proof of Proposition 1}

Condition (10) can be restated as

$$
\varphi(T) \geq N
$$

where

$$
\varphi(T) \equiv \ln \left[K-\alpha_{1}(T)(K-1)\right] / \ln \left(1+r / p_{1}\right) .
$$

with

$$
K=\frac{\bar{v}-k}{k} \frac{p_{0}-p_{1}}{p_{1}} \geq 1+r / p_{1}
$$

under (11). Under (11), there exists $T \geq 0$ and $N \geq 1$ such that (43) holds. Hence effective driver-record mechanisms exist. Let us first check that $\varphi(T)<N+1$ if $(N, T)$ is an optimal effective mechanism. $\varphi(T)$ is increasing and concave, with $\varphi(0)=0$ and using $\alpha_{1}(T) \rightarrow 0$ when $T \rightarrow+\infty$ gives

$$
\varphi(+\infty) \equiv \lim _{T \rightarrow \infty} \varphi(T)=\ln (K) / \ln \left(1+r / p_{1}\right)>1 .
$$

If $\varphi(T) \geq N+1$, then $(N, T)$ is dominated by $\left(N^{\prime}, T^{\prime}\right)$ with $N^{\prime}=N+$ $1, T^{\prime}=(N+1) T / N$. Hence any optimal effective mechanism is such that $N \leq \varphi(T)<N+1$. 
We may write $W(N, T)=\widehat{W}(N / T, T)$ with

$$
\widehat{W}(x, T) \equiv \lambda \frac{w_{0}-\bar{w}+c / T}{1+p_{0} / \eta_{0} x}+(1-\lambda) \frac{w_{1}-\bar{w}+c / T}{1+p_{1} / \eta_{1} x}+\bar{w}-c / T .
$$

An optimal effective driver-record mechanism maximizes $W(\widetilde{\varphi}(T), T)=$ $\widehat{W}(\widetilde{\varphi}(T) / T, T)$ with respect to $T \geq 0$, where $\widetilde{\varphi}(T)$ is the largest integer inferior or equal to $\varphi(T)$. Using $p_{0}>p_{1}, \eta_{0} \leq \eta_{1}$ and $w_{1}>\bar{w}$ allows us to write

$$
\widehat{W}(x, T)>\frac{\lambda w_{0}+(1-\lambda) w_{1}-\bar{w}-p_{0} c /(x T)}{1+p_{0} / \eta_{0} x}+\bar{w}
$$

Hence

$$
W(\widetilde{\varphi}(T), T)>\frac{\lambda w_{0}+(1-\lambda) w_{1}-\bar{w}-p_{0} c / \widetilde{\varphi}(T)}{1+p_{0} T / \eta_{0} \widetilde{\varphi}(T)}+\bar{w}
$$

Assume

$$
c<\frac{\eta_{0} \widetilde{\varphi}(+\infty)\left[\lambda w_{0}+(1-\lambda) w_{1}-\bar{w}\right]}{p_{0}} \equiv \hat{c} .
$$

Then there exists $T>0$ such that $W(\widetilde{\varphi}(T), T)>\bar{w}$. Furthermore, using $\widetilde{\varphi}(T) / T \rightarrow 0$ when $T \longrightarrow+\infty$ gives

$$
\lim _{T \longrightarrow+\infty} W(\widetilde{\varphi}(T), T)=\widehat{W}(0,+\infty)=\bar{w} .
$$

which proves that $T \rightarrow W(\widetilde{\varphi}(T), T)$ reaches a maximum over $R^{+}$when $c<\hat{c}$.

\section{A.4 Proof of Proposition 2}

We first begin by characterizing the sequence defined by (18). We have

Lemma 7. Let $u_{n}$ be an infinite sequence defined by (18) for $n=1,2, \ldots,+\infty$ with $u_{0} \leq \bar{v} / r$. Then $u_{n}$ is increasing, $u_{n}-u_{n-1}$ is decreasing and $u_{n} \rightarrow \bar{v} / r$ as $n \rightarrow+\infty$.

Proof. Using (17), we have $u_{n}>u_{n-1}$ if $u_{n-1}>u_{n-2}$ for all $n \geq 2$, and it is easy to show that $u_{1}>u_{0}$ under the assumption $u_{0}<\bar{v} / r$. Consequently, the sequence $u_{n}$ is increasing. (17) also implies that $u_{n} \leq \bar{v} / r$ for all $n$. The sequence $u_{n}$ is thus increasing and upward bounded, hence it is converging and (17) shows that its limits is $\bar{v} / r$. 
Define $x_{n} \equiv u_{n}-u_{n-1}$ for all $n \geq 2$. (17) gives

$$
\left(r+p_{1}\right) x_{n}+\min \left\{k,\left(p_{0}-p_{1}\right) x_{n}\right\}=p_{1} x_{n-1}+\min \left\{k,\left(p_{0}-p_{1}\right) x_{n-1}\right\}
$$

The LHS of (44) is an increasing functions of $x_{n}$. Likewise, the RHS of (44) is an increasing function of $x_{n-1}$. Consequently, (44) defines $x_{n}$ as an increasing function of $x_{n-1}$. Hence, we have $x_{n} \geq x_{n-1}$ for all $n \geq 2$ iff $x_{2} \geq x_{1}$. In other words, the sequence $u_{n}-u_{n-1}$ is monotonic with respect to $n$. Because $u_{n}$ converges to $\bar{v} / r$ and $u_{n}$ is increasing, we deduce that $u_{n}-u_{n-1}$ is decreasing.

We can now proceed to the proof of proposition 2

Proof. Let $u_{n}, n \in\{0, \ldots, N\}$ be a sequence of equilibrium expected utility for the point-record mechanism $(N, T)$ with $u_{0} \leq \bar{v} / r$. For this sequence, any optimal strategy of normal drivers is such that

$$
s_{n}= \begin{cases}1 & \text { if } u_{n}-u_{n-1}>k /\left(p_{0}-p_{1}\right) \\ y \in[0,1] & \text { if } u_{n}-u_{n-1}=k /\left(p_{0}-p_{1}\right) \\ 0 & \text { if } u_{n}-u_{n-1}<k /\left(p_{0}-p_{1}\right) .\end{cases}
$$

The Proposition follows from the fact that $u_{n}-u_{n-1}$ is decreasing as shown in Lemma 7.

\section{A.5 Proof of Proposition 3}

Let $\tilde{W}$ be the social welfare for equilibrium mixed strategy and utility profile $s_{1}, \ldots, s_{N}, u_{1, \ldots}, u_{N}$ associated with the point-record mechanism $(N, T)$. Assume that $(N, T)$ is not an effective mechanism. Proposition 2 implies that there exists $N^{*}$ in $\{1, \ldots, N-1\}$ and equilibrium strategy $s_{n}=1$ if $n \leq N^{*}$ and $s_{n}=0$ if $n>N^{*} .{ }^{13}$ We then have

$$
\begin{aligned}
\tilde{W} & =\left[\lambda q_{0}+(1-\lambda) q_{1}(1-\tilde{f})\right] w_{0}+(1-\lambda) q_{1} \tilde{f} w_{1} \\
& +\left[\lambda\left(1-q_{0}\right)+(1-\lambda)\left(1-q_{1}\right)\right](\bar{w}-c / T)
\end{aligned}
$$

where $q_{0}$ and $q_{1}$ are defined by (14) for $e \in\{0,1\}$, and $\tilde{f}$ is the proportion of individuals who choose $e=1$ among the population of normal drivers who are entitled to drive. We have

$$
\tilde{f}=\sum_{n=1}^{N} f_{n} s_{n}
$$

\footnotetext{
${ }^{13}$ Proposition 2 says that $s_{N^{*}} \in[0,1]$. However if $u_{N^{*}}-u_{N^{*}-1}=k /\left(p_{0}-p_{1}\right)$ then $s_{N^{*}}=1$ is an equilibrium strategy. Otherwise $N^{*}$ can be chosen such that $\left\{s_{n}=1\right.$ if $n \leq N^{*}$ and $s_{n}=0$ if $\left.n>N^{*}\right\}$ is an equilibrium strategy.
} 
where $f_{n}$ denotes the proportion of $n$-points drivers among normal drivers allowed to drive (i.e. who have at least one point). These proportions are derived as follow. At steady states we have

$$
\left(1-q_{1}\right) \eta_{1} / T=q_{1} f_{1} \tilde{p}_{1}=q_{1} f_{2} \tilde{p}_{2}=\ldots=q_{1} f_{N} \tilde{p}_{N}
$$

where $\tilde{p}_{n}=s_{n} p_{1}+\left(1-s_{n}\right) p_{0}$ is the instantaneous rate at which a $n$-point normal driver is caught committing an infraction and thus loses a point. Using $\sum_{n=1}^{N} f_{n}=1$ gives

$$
\sum_{n=1}^{N} \frac{f_{n} \tilde{p}_{n}}{\tilde{p}_{n}}=f_{1} \tilde{p}_{1} \sum_{n=1}^{N}\left(1 / \tilde{p}_{n}\right)=1
$$

which yields

$$
f_{n}=\frac{1 / \tilde{p}_{n}}{\sum_{m=1}^{N}\left(1 / \tilde{p}_{m}\right)} \text { for all } n=1, \ldots, N
$$

and using (45)

$$
q_{1}=\frac{\eta_{1} / T}{\eta_{1} / T+f_{1} \tilde{p}_{1}}=\frac{\sum_{n=1}^{N}\left(1 / \tilde{p}_{n}\right)}{\sum_{n=1}^{N}\left(1 / \tilde{p}_{n}\right)+T / \eta_{1}}
$$

We thus have

$$
\tilde{f}=\frac{\sum_{n=1}^{N} s_{n} / \tilde{p}_{n}}{\sum_{n=1}^{N}\left(1 / \tilde{p}_{n}\right)}
$$

and

$$
q_{1} \tilde{f}=\frac{\sum_{n=1}^{N} s_{n} / \tilde{p}_{n}}{\sum_{n=1}^{N}\left(1 / \tilde{p}_{n}\right)+T / \eta_{1}} .
$$

We also have

$$
\sum_{n=1}^{N} s_{n} / \tilde{p}_{n}=\sum_{n=1}^{N^{*}} 1 / p_{1}=\frac{N^{*}}{p_{1}}
$$

and

$$
\begin{aligned}
\sum_{n=1}^{N}\left(1 / \tilde{p}_{n}\right) & =\sum_{n=1}^{N^{*}}\left(1 / p_{1}\right)+\sum_{n=N^{*}+1}^{N}\left(1 / p_{0}\right) \\
& =N^{*} / p_{1}+\left(N-N^{*}\right) / p_{0}
\end{aligned}
$$


which yields

$$
q_{1} \tilde{f}=\frac{N^{*} / p_{1}}{N^{*} / p_{1}+\left(N-N^{*}\right) / p_{0}+T / \eta_{1}}
$$

Let us show that $\left(N^{*}, T^{*}\right)$ is an effective mechanism that dominates $(N, T)$. The first step is to show that $\left(N^{*}, T\right)$ is effective. Let $u_{n}^{*}, n \in$ $\left\{0,1, \ldots, N^{*}\right\}$, be a sequence of equilibrium life-time expected utility of a normal driver for $N^{*}, T$. i.e. $u_{n}^{*}$ is defined by (18) with the boundary condition $u_{0}^{*}=\alpha_{1}(T) u_{N^{*}}^{*}$. Using the fact that (44) holds for all $n=1, \ldots, N^{*}$ at the same time for the sequences $u_{n}$ and $u_{n}^{*}$, we deduce that $u_{N^{*}}^{*}-u_{N^{*}-1}^{*} \geq$ $u_{N^{*}}-u_{N^{*}-1}$ if and only if $u_{1}^{*}-u_{0}^{*} \geq u_{1}-u_{0}$ or equivalently, from (18), if $u_{0}^{*} \leq u_{0}$. Since $u_{0}^{*}=\alpha_{1}(T) u_{N^{*}}^{*}$ and $u_{0}=\alpha_{1}(T) u_{N^{*}}$, this condition is equivalent to $u_{N^{*}}^{*} \leq u_{N}$, which is true because reducing the number of points entails a decrease in the life-time expected utility of a normal driver with a fresh record. Consequently $u_{N^{*}}^{*}-u_{N^{*}-1}^{*} \geq u_{N^{*}}-u_{N^{*}-1} \geq k /\left(p_{0}-p_{1}\right)$ and thus $\left(N^{*}, T\right)$ is effective. It remains to show that $\left(N^{*}, T\right)$ dominates $(N, T)$. Let $W^{*}$ be the social welfare under the $\left(N^{*}, T\right)$ mechanism and let $q_{e}^{*}$ be the proportion of type- $e$ individuals who are entitled to drive under $\left(N^{*}, T\right) . q_{e}^{*}$ is given by (14) where $N^{*}$ is substituted to $N$, i.e.

$$
q_{e}^{*}=\frac{N^{*} / p_{e}}{N^{*} / p_{e}+T / \eta_{e}}
$$

Using (46) and $N^{*}<N$ shows that

$$
q_{0}^{*}<q_{0} \quad \text { and } \quad q_{1}^{*}>q_{1} \tilde{f}
$$

(12) gives

$W^{*}=\lambda\left[\bar{w}-c / T-q_{0}^{*}\left(\bar{w}-c / T-w_{0}\right)\right]+(1-\lambda)\left[\bar{w}-c / T+q_{1}^{*}\left(w_{1}-\bar{w}+c / T\right)\right]$

Using (47), (48), $\bar{w}-c / T-w_{0}>0$ and $w_{1}-\bar{w}+c / T>0$ allows us to write

$$
\begin{aligned}
W^{*} & >\lambda\left[\bar{w}-c / T-q_{0}\left(\bar{w}-c / T-w_{0}\right)\right] \\
& +(1-\lambda)\left[\bar{w}-c / T+q_{1} \tilde{f}\left(w_{1}-\bar{w}+c / T\right)\right] \\
& >\lambda\left[\bar{w}-c / T-q_{0}\left(\bar{w}-c / T-w_{0}\right)\right] \\
& +(1-\lambda)\left[\bar{w}-c / T+q_{1} \tilde{f}\left(w_{1}-\bar{w}+c / T\right)+q_{1}(1-\tilde{f})\left(w_{0}-\bar{w}+c / T\right)\right] \\
& =\tilde{W}
\end{aligned}
$$

which completes the proof. 


\section{B Properties of redemptive mechanisms}

\section{B.1 Proof of Lemma 3}

Setting $t=0$ in (23) yields

$$
u_{n}^{0}=\frac{\bar{v}-k+p_{1} u_{n-1}^{0}}{r+p_{1}} \gamma(M)+[1-\gamma(M)] u_{N} \quad \text { for } n=0, \ldots, N .
$$

which gives

$$
u_{n}^{0}=\left[a(\gamma(M))+(1-\gamma(M)) u_{N}\right] \frac{1-b^{n} \gamma(M)^{n}}{1-b \gamma(M)}+b^{n} \gamma(M)^{n} u_{0}
$$

Using $u_{0}=\sigma_{1}(T) u_{N}$ along with $u_{N}^{0}=u_{N}$ yields

$$
u_{N}=\frac{a \gamma(M)\left(1-b^{N} \gamma(M)^{N}\right)}{[1-b \gamma(M)]\left[1-b^{N} \gamma(M)^{N} \sigma_{1}(T)\right]-[1-\gamma(M)]\left[1-b^{N} \gamma(M)^{N}\right]}
$$

which in turn gives (25).

Differentiating (22), we obtain that

$$
u_{n}^{\prime}(t)=\left(r+p_{1}\right)[1-\gamma(M-t)]\left(u_{N}-a-b u_{n-1}^{0}\right)
$$

As $u_{n}^{0}$ is increasing in $n$, we have $u_{n}^{\prime}(t)>0$ for all $t<M$ if $u_{N}>a+b u_{0}$ where $u_{0}=\sigma_{1}(T) u_{N}$, which leads to

$$
u_{N}>\frac{a}{1-b \sigma_{1}(T)}
$$

Using (50), it is straightforward to verify that this condition is satisfied, hence that $u_{n}^{\prime}(t)>0$ for all $t<M$ and $n<N$.

\section{B.2 Proof of Lemma 4}

(29) can be written as

$$
q_{n}^{0}=q_{N}^{0}[1-x(M)]^{N-n-1}
$$

where $x(M) \equiv e^{-p M}$ and (30) simplifies to

$$
\begin{aligned}
q_{N}^{0} & =(1-q) \eta / T+x(M) \sum_{n=1}^{N-1} q_{n}^{0} \\
& =(1-q) \eta / T+x(M) q_{N}^{0} \sum_{n=0}^{N-2}[1-x(M)]^{n} \\
& =(1-q) \eta / T+\left\{1-[1-x(M)]^{N-1}\right\} q_{N}^{0}
\end{aligned}
$$


which yields

$$
q_{N}^{0}=\frac{(1-q) \eta}{T[1-x(M)]^{N-1}}
$$

We also have

$$
\int_{0}^{+\infty} q_{N}(t) d t=\frac{q_{N}^{0}}{p}
$$

and

$$
\begin{aligned}
\sum_{n=1}^{N-1} \int_{0}^{M} q_{n}(t) d t & =\frac{1-x(M)}{p} \sum_{n=1}^{N-1} q_{n}^{0} \\
& =\frac{1-x(M)}{p} q_{N}^{0} \sum_{n=0}^{N-2}(1-x(M))^{n} \\
& =\frac{1-x(M)}{p} \frac{1-(1-x(M))^{N-1}}{x(M)} q_{N}^{0}
\end{aligned}
$$

Consequently, (31) simplifies to

$$
q=\frac{q_{N}^{0}}{p}\left((1-x(M)) \frac{1-(1-x(M))^{N-1}}{x(M)}+1\right)=\frac{q_{N}^{0}}{p} \frac{1-(1-x(M))^{N}}{x(M)}
$$

Collecting terms and simplifying give (32). Using $(1-x)^{N}=\sum_{k=0}^{N}\left({ }_{N}^{k}\right)(-x)^{N-k}$ where $\left(\begin{array}{l}k \\ N\end{array}\right)=N ! /[k !(N-k) !]$ yields

$$
\begin{aligned}
y(N, x) & =\frac{x \sum_{k=0}^{N-1}\left(\begin{array}{c}
k \\
N-1
\end{array}\right)(-x)^{N-1-k}}{1-\sum_{k=0}^{N}\left(\begin{array}{l}
k \\
N
\end{array}\right)(-x)^{N-k}} \\
& =\frac{1}{N} \frac{\sum_{k=0}^{N-1}\left(\begin{array}{c}
k \\
N-1
\end{array}\right)(-x)^{N-1-k}}{\sum_{k=0}^{N-1}\left(\begin{array}{l}
k \\
N-1
\end{array}\right)(-x)^{N-k-1} /(N-k)}
\end{aligned}
$$

which gives $y(N, 0)=1 / N$ and using $N \geq 2$

$$
\frac{\partial y}{\partial x}=\frac{(1-x)^{N-2}\left[1-N x-(1-x)^{N}\right]}{\left[1-(1-x)^{N}\right]^{2}}<0 .
$$




\section{B.3 Proof of Proposition 5}

Denote by $x_{e}(M) \equiv e^{-p_{e} M}$ for $e=0,1$. We have $x_{0}(M)=x_{1}(M)^{\rho}$ where $\rho=p_{0} / p_{1}>1$ and using (24), we also have $\gamma(M)=1-x_{1}(M)^{\mu}$ where $\mu=1+r / p_{1}$. Consequently, the social welfare (12) may be written as

$W\left(N, T, X_{0}\left(x_{1}\right), x_{1}\right)=\frac{\lambda\left(w_{0}-\bar{w}+c / T\right)}{1+y\left(N, X_{0}\left(x_{1}\right)\right) p_{0} T / \eta_{0}}+\frac{(1-\lambda)\left(w_{1}-\bar{w}+c / T\right)}{1+y\left(N, x_{1}\right) p_{1} T / \eta_{1}}+\bar{w}-c / T$

where $X_{0}(x)=x^{\rho}$. (28) may be rewritten as

$$
G\left(N, T, \tau\left(x_{1}\right)\right) \geq 0
$$

where $\tau(x) \equiv 1-x^{\mu}$ and $G(\cdot)$ is given by

$$
G(N, T, \tau)=\frac{a}{b} \frac{p_{0}-p_{1}}{k}-1-\frac{\tau(1-b)\left(1-b^{N} \tau^{N}\right)}{[1-b \tau]\left(1-\sigma_{1}(T)\right) b^{N} \tau^{N}}
$$

Define $\phi$ as

$$
\phi(x)=\max _{N, T}\left\{W\left(N, T, X_{0}(x), x\right): G(N, T, \tau(x)) \geq 0\right\}
$$

Note that $x_{1}$ goes to zero when $M$ goes to infinity. Hence the proposition will be proved if we show that $\phi^{\prime}(0)>0$. Using the envelope theorem allows us to write

$$
\phi^{\prime}(0)=\frac{\partial W(N, T, 0,0)}{\partial x_{0}} X_{0}^{\prime}(0)+\frac{\partial W(N, T, 0,0)}{\partial x_{1}}+\gamma \frac{\partial G(N, T, 1,0)}{\partial \tau} \tau^{\prime}(0)
$$

where $\gamma$ is the Kuhn and Tucker multiplier corresponding to (28).

We have

$$
\frac{\partial W(N, T, 0,0)}{\partial x_{0}}=-\frac{\lambda\left(w_{0}-\bar{w}+c / T\right) p_{0} T / \eta_{0}}{\left[1+y(N, 0) p_{0} T / \eta_{0}\right]^{2}} \frac{\partial y(N, T, 0)}{\partial x}
$$

where $y(N, T, 0)=1 / N$. A tedious calculation gives $\partial y(N, 0) / \partial x=-(N-$ $1) / 2 N$ and thus

$$
\frac{\partial W(N, T, 0,0)}{\partial x_{0}}=\frac{\lambda\left(w_{0}-\bar{w}+c / T\right) p_{0} T / \eta_{0}}{\left(1+p_{0} T / \eta_{0} N\right)^{2}} \frac{N-1}{2 N}
$$

Similar computations give

$$
\frac{\partial W(N, T, 0,0)}{\partial x_{1}}=\frac{(1-\lambda)\left(w_{1}-\bar{w}+c / T\right) p_{1} T / \eta_{1}}{\left(1+p_{1} T / \eta_{1} N\right)^{2}} \frac{N-1}{2 N}
$$


Finally, using (28), straightforward computations give

$$
\frac{\partial G(N, T, 1)}{\partial \tau}=-\frac{\left(1-b^{N}\right)(1-N)-N b^{N}(1-b)^{2}}{[1-b]\left[1-\sigma_{1}(T)\right] b^{N}}
$$

while

$$
\gamma=\frac{\lambda\left(w_{0}-\bar{w}+c / T\right)}{\left(1+p_{0} T / \eta_{0} N\right)^{2}} \frac{p_{0} T}{\eta_{0} N^{2}}+\frac{(1-\lambda)\left(w_{1}-\bar{w}+c / T\right)}{\left(1+p_{1} T / \eta_{1} N\right)^{2}} \frac{p_{1} T}{\eta_{1} N^{2}}
$$

using (12) and (43). Since $X_{0}^{\prime}(0)=\tau^{\prime}(0)=0$, we thus have $\phi^{\prime}(0)=$ $\partial W(N, T, 0,0) / \partial x_{1}>0$ which completes the proof.

\section{Properties of probationary licences}

\section{C.1 Proof of Lemma 5}

Using (34) for $\ell=0$ gives

$$
\begin{aligned}
u(0)-\hat{u}_{R-1} & =u_{N}-\gamma(L)\left(u_{N}-\hat{u}_{R}\right)-\hat{u}_{R-1} \\
& =\hat{u}_{R}-\hat{u}_{R-1}+[1-\gamma(L)]\left(u_{N}-\hat{u}_{R}\right) \\
& \geq \hat{u}_{R}-\hat{u}_{R-1} \\
& \geq k /\left(p_{0}-p_{1}\right)
\end{aligned}
$$

where the first inequality comes from $u_{N} \geq \hat{u}_{R}$ and the last inequality comes from $R \leq \varphi\left(T^{\prime}\right)$ when $\left(R, T^{\prime}\right)$ is effective.

\section{C.2 Proof of Lemma 6}

Given that drivers are renewed at rate $\pi$, we have

$$
\widetilde{q}^{e}(\ell)=\pi e^{-\left(\pi+p_{e}\right) \ell}
$$

The total proportion of new type-e drivers in probationary phase is thus given by

$$
\int_{0}^{L} \widetilde{q}^{e}(\ell) d \ell=\frac{\pi-\widetilde{q}^{e}(L)}{\pi+p_{e}}
$$

At a steady state, the proportion of older drivers in each category is such that the flow of incoming drivers compensates for the outgoing ones. We thus have $\left(\pi+p_{e}\right) q_{n}^{e}=p_{e} q_{n+1}^{e}$ for $n=1, \ldots, N-1$, which gives

$$
q_{n}^{e}=q_{N}^{e} \chi_{e}^{N-n} \text { for } n=1, \ldots, N-1
$$


where $\chi_{e}=p_{e} /\left(\pi+p_{e}\right)$. Hence, we have

$$
\sum_{n=1}^{N} q_{n}^{e}=q_{N}^{e} \frac{1-\chi_{e}^{N}}{1-\chi_{e}}
$$

The proportion of type-e drivers deprived of their licences since time $t \in$ $[\theta T,(\theta+1) T), \theta \in \mathbb{N}$ is given by

$$
q_{0}^{e}(\theta, t)=p_{e} q_{1}^{e}\left(1-\eta_{e}\right)^{\theta} \exp (-\pi t)
$$

and we also have

$$
\left(\pi+p_{e}\right) q_{N}^{e}=\widetilde{q}^{e}(L)+\eta_{e} \sum_{\theta=0}^{\infty} q_{0}^{e}(\theta,(\theta+1) T)
$$

Indeed, at steady states, the flow of successful beginners at the end of their probationary phase and of old drivers who have passed examinations must compensate for the disappearance of $N$ points drivers who were either convicted or no longer alive.

Define

$$
\beta_{e}=\frac{\eta_{e} e^{-\pi T}}{1-\left(1-\eta_{e}\right) e^{-\pi T}}
$$

We get

$$
q_{N}^{e}=\frac{\widetilde{q}^{e}(L)}{\pi+p_{e}}+\beta_{e} q_{1}^{e} \chi_{e}=\frac{\widetilde{q}^{e}(L)}{\pi+p_{e}}+q_{N}^{e} \chi_{e}^{N} \beta_{e}
$$

which gives

$$
q_{N}^{e}=\frac{\widetilde{q}^{e}(L)}{\left(\pi+p_{e}\right)\left(1-\beta_{e} \chi_{e}^{N}\right)}
$$

and thus

$$
\begin{aligned}
\sum_{n=1}^{N} q_{n}^{e} & =\frac{\widetilde{q}^{e}(L) /\left(\pi+p_{e}\right)}{1-\beta_{e} \chi_{e}^{N}} \frac{1-\chi_{e}^{N}}{1-\chi_{e}} \\
& =\frac{\widetilde{q}^{e}(L)}{\pi} \frac{1-\chi_{e}^{N}}{1-\beta_{e} \chi_{e}^{N}}
\end{aligned}
$$

Similarly, at a steady state we have $\hat{q}_{r}^{e}=\hat{q}_{R-1}^{e} \chi_{e}^{R-1-r}$ for $r=1, \ldots, R-2$, with

$$
\left(\pi+p_{e}\right) \hat{q}_{R-1}^{e}=p_{e}\left(\hat{q}_{R}^{e}+\int_{0}^{L} \widetilde{q}^{e}(\ell) d \ell\right)
$$


since beginners who infringe rules are given a $R$-point licence only, with a record already decreased of one point, and with

$$
\left(\pi+p_{e}\right) \hat{q}_{R}^{e}=p_{e} \hat{q}_{1}^{e} \eta_{e} \sum_{\theta=0}^{\infty}\left(1-\eta_{e}\right)^{\theta} \exp \left\{-\pi(\theta+1) T^{\prime}\right\}
$$

Collecting terms gives

$$
\hat{q}_{R}^{e}=\hat{q}_{R-1}^{e} \chi^{R-1} \beta_{e}^{\prime}
$$

with $\beta_{e}^{\prime}=\eta_{e} \exp \left\{-\pi T^{\prime}\right\} /\left[1-\left(1-\eta_{e}\right) \exp \left\{-\pi T^{\prime}\right\}\right]$, which yields

$$
\begin{aligned}
&\left(\pi+p_{e}\right) \hat{q}_{R-1}^{e}=p_{e}\left(\hat{q}_{R-1}^{e} \chi_{e}^{R-1} \beta_{e}^{\prime}+\int_{0}^{L} \widetilde{q}^{e}(\ell) d \ell\right) \\
&=p_{e}\left(\hat{q}_{R-1}^{e} \chi_{e}^{R-1} \beta_{e}^{\prime}+\frac{\pi-\widetilde{q}^{e}(L)}{\pi+p_{e}}\right) \\
& \hat{q}_{R-1}^{e}\left(1-\chi_{e}^{R} \beta_{e}^{\prime}\right)=\chi_{e} \frac{\pi-\widetilde{q}^{e}(L)}{\pi+p_{e}} \\
& \hat{q}_{R-1}^{e}=\frac{\chi_{e}\left(\pi-\widetilde{q}^{e}(L)\right)}{\left(1-\beta_{e}^{\prime} \chi_{e}^{R}\right)\left(\pi+p_{e}\right)}
\end{aligned}
$$

and thus

$$
\begin{aligned}
\sum_{r=1}^{R} \hat{q}_{r}^{e} & =\hat{q}_{R}^{e}+\sum_{r=1}^{R-1} \hat{q}_{r}^{e} \\
& =\beta_{e}^{\prime} \hat{q}_{R-1}^{e} \chi_{e}^{R-1}+\sum_{r=1}^{R-1} \hat{q}_{R-1}^{e} \chi_{e}^{R-1-r} \\
& =\frac{\chi_{e}\left(\pi-\widetilde{q}^{e}(L)\right)}{\left(1-\beta_{e}^{\prime} \chi_{e}^{R}\right)\left(\pi+p_{e}\right)}\left[\beta_{e}^{\prime} \chi_{e}^{R-1}+\frac{\pi+p_{e}}{\pi}\left(1-\chi_{e}^{R-1}\right)\right] \\
& =\frac{\pi-\widetilde{q}^{e}(L)}{\pi} \frac{\pi \beta_{e}^{\prime} \chi_{e}^{R}+p_{e}\left(1-\chi_{e}^{R-1}\right)}{\left(1-\beta_{e}^{\prime} \chi_{e}^{R}\right)\left(\pi+p_{e}\right)}
\end{aligned}
$$

Finally,

$$
\begin{aligned}
q^{e} & =\frac{\pi-\widetilde{q}^{e}(L)}{\pi+p_{e}}+\frac{\widetilde{q}^{e}(L)}{\pi} \frac{1-\chi_{e}^{N}}{1-\beta_{e} \chi_{e}^{N}}+\frac{\pi-\widetilde{q}^{e}(L)}{\pi} \frac{\pi \beta_{e}^{\prime} \chi_{e}^{R}+p_{e}\left(1-\chi_{e}^{R-1}\right)}{\left(1-\beta_{e}^{\prime} \chi^{R}\right)\left(\pi+p_{e}\right)} \\
& =\frac{\widetilde{q}^{e}(L)}{\pi} \frac{1-\chi_{e}^{N}}{1-\beta_{e} \chi_{e}^{N}}+\frac{\pi-\widetilde{q}^{e}(L)}{\pi} \frac{1-\chi_{e}^{R}}{1-\beta_{e}^{\prime} \chi_{e}^{R}} .
\end{aligned}
$$




\section{C.3 Proof of Proposition 6}

Lemma 6 shows that the optimal point-record system maximizes

$$
\begin{aligned}
W & =\lambda\left\{e^{-\left(\pi+p_{0}\right) L}\left[\Phi\left(p_{0}, N, T\right) w_{0}+\left(1-\Phi\left(p_{0}, N, T\right)\right)(\bar{w}-c / T)\right]\right. \\
& \left.+\left(1-e^{-\left(\pi+p_{0}\right) L}\right)\left[\Phi\left(p_{0}, R, T^{\prime}\right) w_{0}+\left(1-\Phi\left(p_{0}, R, T^{\prime}\right)\right)(\bar{w}-c / T)\right]\right\} \\
& +(1-\lambda)\left\{e^{-\left(\pi+p_{1}\right) L}\left[\Phi\left(p_{1}, N, T\right) w_{1}+\left(1-\Phi\left(p_{1}, N, T\right)\right)(\bar{w}-c / T)\right]\right. \\
& \left.+\left(1-e^{-\left(\pi+p_{1}\right) L}\right)\left[\Phi\left(p_{1}, R, T^{\prime}\right) w_{1}+\left(1-\Phi\left(p_{1}, R, T^{\prime}\right)\right)(\bar{w}-c / T)\right]\right\}
\end{aligned}
$$

with respect to $N, R \in \mathbb{N}^{*}, T, T^{\prime} \geq 0$, subject to $N \leq \varphi(T)$ and $R \leq \varphi\left(T^{\prime}\right)$. Let

$$
\begin{aligned}
\mu & =\lambda e^{-\left(\pi+p_{0}\right) L}+(1-\lambda) e^{-\left(\pi+p_{1}\right) L} \\
\widetilde{\lambda} & =\frac{\lambda e^{-\left(\pi+p_{0}\right) L}}{\mu} \\
\widetilde{\lambda}^{\prime} & =\frac{\lambda\left(1-e^{-\left(\pi+p_{0}\right) L}\right)}{1-\mu}
\end{aligned}
$$

We may write

$$
\begin{aligned}
W & =\mu\left\{\tilde{\lambda}\left[\Phi\left(p_{0}, N, T\right) w_{0}+\left(1-\Phi\left(p_{0}, N, T\right)\right)(\bar{w}-c / T)\right]\right. \\
& \left.+(1-\widetilde{\lambda})\left[\Phi\left(p_{1}, N, T\right) w_{1}+\left(1-\Phi\left(p_{1}, N, T\right)\right)(\bar{w}-c / T)\right]\right\} \\
& +(1-\mu)\left\{\widetilde{\lambda}^{\prime}\left[\Phi\left(p_{0}, R, T^{\prime}\right) w_{0}+\left(1-\Phi\left(p_{0}, R, T^{\prime}\right)\right)(\bar{w}-c / T)\right]\right. \\
& \left.+\left(1-\widetilde{\lambda}^{\prime}\right)\left[\Phi\left(p_{1}, R, T^{\prime}\right) w_{1}+\left(1-\Phi\left(p_{1}, R, T^{\prime}\right)\right)(\bar{w}-c / T)\right]\right\}
\end{aligned}
$$

so that the maximisation problem can be decomposed in two separare subproblems. The first one determines $N, T$ by maximizing

$$
\begin{aligned}
& \tilde{\lambda}\left[\Phi\left(p_{0}, N, T\right) w_{0}+\left(1-\Phi\left(p_{0}, N, T\right)\right)(\bar{w}-c / T)\right] \\
& +(1-\widetilde{\lambda})\left[\Phi\left(p_{1}, N, T\right) w_{0}+\left(1-\Phi\left(p_{1}, N, T\right)\right)(\bar{w}-c / T)\right]
\end{aligned}
$$

subject to $N \leq \varphi(T)$. The second subproblem gives $R, T^{\prime}$ by maximizing

$$
\begin{aligned}
& \widetilde{\lambda}^{\prime}\left[\Phi\left(p_{0}, R, T^{\prime}\right) w_{0}+\left(1-\Phi\left(p_{0}, R, T^{\prime}\right)\right)(\bar{w}-c / T)\right] \\
& +\left(1-\widetilde{\lambda}^{\prime}\right)\left[\Phi\left(p_{1}, R, T^{\prime}\right) w_{0}+\left(1-\Phi\left(p_{1}, R, T^{\prime}\right)\right)(\bar{w}-c / T)\right]
\end{aligned}
$$

subject to $R \leq \varphi\left(T^{\prime}\right)$. Observe that these two subproblems are identical up to the parameter $\widetilde{\lambda}$ in the first one, or $\widetilde{\lambda}^{\prime}$ in the second one, and the optimal solution depends on this parameter. $p_{0} \neq p_{1}$ implies $\widetilde{\lambda} \neq \tilde{\lambda}^{\prime}$ and thus $(N, T) \neq\left(R, T^{\prime}\right)$. 


\section{Proof of Proposition 7}

First observe that $\phi\left(s^{\prime}, s^{\prime \prime}, n, N, T\right)$ is decreasing in $n$ when $s^{\prime \prime}$ is close to 1 . In that case, (37) holds for all $n$ if

$$
\phi\left(s^{\prime}, s^{\prime \prime}, N, N, T\right) \geq \frac{k}{a\left[1-\sigma_{1}(T)\right]}
$$

Lemma 8. $\frac{\partial \phi\left(s^{\prime}, 1, N, N, T\right)}{\partial s^{\prime \prime}}<0$ when $f_{0}(1) / f_{1}(1)$ is large enough.

Proof. Simple computations yield

$\frac{\partial \phi\left(s^{\prime}, 1, N, N, T\right)}{\partial s^{\prime \prime}}=f_{0}(1)\left(\frac{d \phi\left(s^{\prime}, 1, N, N, T\right)}{d \mu_{0}} \frac{\pi_{0}}{p_{e}}+\frac{f_{1}(1)}{f_{0}(1)} \frac{d \phi\left(s^{\prime}, 1, N, N, T\right)}{d \mu_{1}} \frac{\pi_{1}}{p_{e}}\right)$

where

$$
\begin{gathered}
\frac{d \phi\left(s^{\prime}, 1, N, N, T\right)}{d \mu_{0}} \equiv \frac{-p_{0}\left(1-b^{N-1}\right)}{(1-b)\left[1-\sigma_{1}(T) b^{N}\right]}<0 \\
\frac{d \phi\left(s^{\prime}, 1, N, N, T\right)}{d \mu_{1}} \equiv \frac{b^{N-1}\left(p_{0}-p_{1}\right)\left[N(1-b)+b\left(1-\sigma_{1}(T)\right)\right]-\left(p_{0} b^{N-1}-p_{1}\right)\left[1-\sigma_{1}(T) b^{N}\right]}{(1-b)\left[1-\sigma_{1}(T) b^{N}\right]^{2}}>0
\end{gathered}
$$

We thus have

$$
\frac{\partial \phi\left(s^{\prime}, 1, N, N, T\right)}{\partial s^{\prime \prime}}<0 \text { if } \frac{f_{0}(1)}{f_{1}(1)}>-\frac{d \phi\left(s^{\prime}, 1, N, N, T\right) / d \mu_{1}}{d \phi\left(s^{\prime}, 1, N, N, T\right) / d \mu_{0}}>0
$$

We can now proceed to the proof of proposition 7

Proof. Let $W\left(s^{\prime \prime}, N\right)$ the value function of the maximization problem constrained by given values of $s^{\prime \prime}$ and $N$, with $\gamma>0$ the multiplier associated to (37) and let $\hat{s}^{\prime}, \hat{T}$ and $\hat{N}$ be optimal values of $s^{\prime}, T$ and $N$ when $s^{\prime \prime}$ is fixed at $s^{\prime \prime}=1$. Using $z_{e}(1, N)=1 / N, \partial z_{e}(1, N) / \partial \mu=-(N-1) /(2 N)$, the envelope theorem yields

$$
\begin{aligned}
\frac{\partial W(1, \hat{N})}{\partial s^{\prime \prime}} & =\frac{\hat{N}-1}{2 \hat{N}}\left(\frac{\lambda\left(w_{0}-\bar{w}+c / \hat{T}\right)}{\left[1+p_{0}\left(\hat{s}^{\prime}\right) \hat{T} /\left(\eta_{0} \hat{N}\right)\right]^{2}} \frac{\pi_{0} \hat{T} f_{0}(1)}{\eta_{0}}+\frac{(1-\lambda)\left(w_{1}-\bar{w}+c / \hat{T}\right)}{\left[1+p_{1}\left(\hat{s}^{\prime}\right) \hat{T} /\left(\eta_{1} \hat{N}\right)\right]^{2}} \frac{\pi_{1} \hat{T} f_{1}(1)}{\eta_{1}}\right) \\
& +\gamma \frac{\partial \phi\left(\hat{s}^{\prime}, 1, \hat{N}, \hat{N}, \hat{T}\right)}{\partial s^{\prime \prime}}
\end{aligned}
$$


Note that $\hat{T} \geq \bar{T}$ and thus $w_{0}-\bar{w}+c / \hat{T}<0$. Hence the bracketed term in the previous formula is negative if

$$
\frac{f_{0}(1)}{f_{1}(1)} \geq \hat{A} \equiv-\frac{1-\lambda}{\lambda} \frac{w_{1}-\bar{w}+c / \hat{T}}{w_{0}-\bar{w}+c / \hat{T}}\left(\frac{\eta_{1} \hat{N}+p_{1}\left(\hat{s}^{\prime}\right) \hat{T}}{\eta_{0} \hat{N}+p_{0}\left(\hat{s}^{\prime}\right) \hat{T}}\right)^{2} \frac{\pi_{0}}{\pi_{1}} \frac{\eta_{0}}{\eta_{1}}>0
$$

Using the previous Lemma, a sufficient condition for $\partial W(1, \widehat{N}) / \partial s^{\prime \prime}$ is then given by

$$
\frac{f_{0}(1)}{f_{1}(1)}>\max \left\{\hat{A},-\frac{d \phi\left(\hat{s}^{\prime}, 1, \hat{N}, \hat{N}, \hat{T}\right) / d \mu_{1}}{d \phi\left(\hat{s}^{\prime}, 1, \hat{N}, \hat{N}, \hat{T}\right) / d \mu_{0}}\right\}
$$

which is a sufficient condition for the optimal value of $s^{\prime \prime}$ to be less than 1 . 


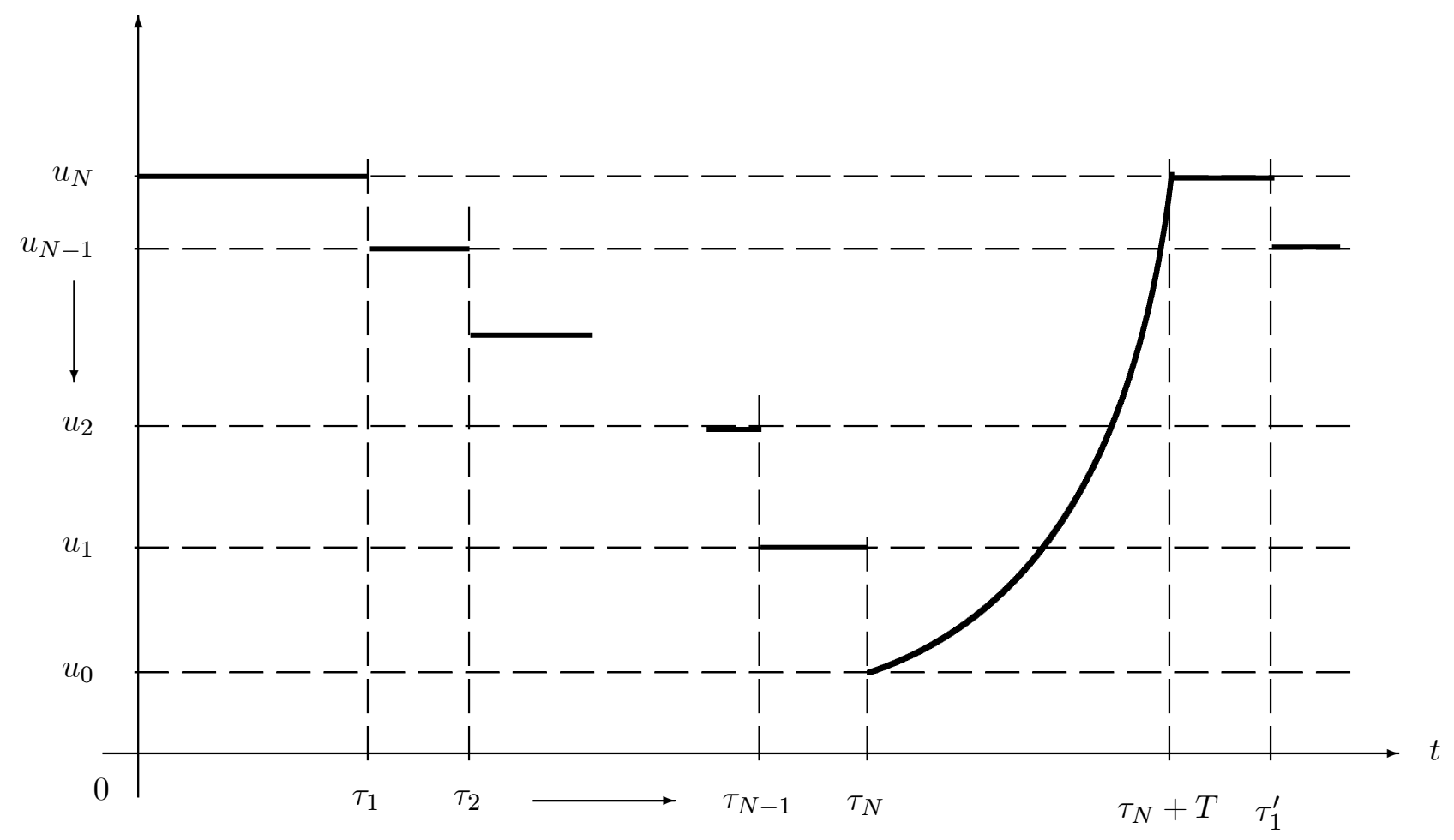

Figure 1: Drivers' utility. The driver loses a first point at $t=\tau_{1}$, a second one at $t=\tau_{2}, \ldots$ Her licence is revocated at $t=\tau_{N}$ and she recovers it first time round at $t=\tau_{N}+T$. 